\title{
Recent Developments in Spectroscopic Techniques for the Detection of Explosives
}

\author{
Wei Zhang *, Yue Tang, Anran Shi, Lirong Bao, Yun Shen, Ruiqi Shen and Yinghua Ye \\ Department of Applied Chemistry, School of Chemical Engineering, Nanjing University of Science and \\ Technology, Nanjing 210094, China; tangyue090@163.com (Y.T.); 114103000380@njust.edu.cn (A.S.); \\ blr1216@njust.edu.cn (L.B); 315103002440@njust.edu.cn (Y.S.); rqshen@njust.edu.cn (R.S.); \\ yyinghua@njust.edu.cn(Y.Y.) \\ * Correspondence: wzhang@njust.edu.cn; Tel.: +86-25-8431-5855
}

Received: 8 July 2018; Accepted: 3 August 2018; Published: 6 August 2018

\begin{abstract}
Trace detection of explosives has been an ongoing challenge for decades and has become one of several critical problems in defense science; public safety; and global counter-terrorism. As a result, there is a growing interest in employing a wide variety of approaches to detect trace explosive residues. Spectroscopy-based techniques play an irreplaceable role for the detection of energetic substances due to the advantages of rapid, automatic, and non-contact. The present work provides a comprehensive review of the advances made over the past few years in the fields of the applications of terahertz (THz) spectroscopy; laser-induced breakdown spectroscopy (LIBS), Raman spectroscopy; and ion mobility spectrometry (IMS) for trace explosives detection. Furthermore, the advantages and limitations of various spectroscopy-based detection techniques are summarized. Finally, the future development for the detection of explosives is discussed.
\end{abstract}

Keywords: explosive detection; terahertz spectroscopy; laser-induced breakdown spectroscopy; Raman spectroscopy; ion mobility spectrometry

\section{Introduction}

Explosives and their related substances are widely used in many military conflicts and for varying civil applications, resulting in different explosives that have been synthesized and manufactured [1]. Figure 1 shows the classifications of the most commonly used explosives.

In recent years, the detection of different kinds of energetic materials has become a high priority problem for anti-terrorism reasons [2,3]. It is also crucial to the protection of human life, infrastructure, and property [4]. Law enforcement forces of different countries around the world need to promote the development of effective detection systems to deal with the problem of concealment of explosives in public places such as airports, railways, or bus stations. Moreover, if terrorist attacks or crimes are successful, the development of an analytical tool to identify the remains of explosives is very important for the forensic rebuild at the site of the explosion [5]. In addition, water contamination, soil pollution, and health problems caused by explosive explosions should be taken into account. Based on these reasons, people need to develop faster and more sensitive explosives analysis methods [6,7].

Due to the importance of rapid, automatic, and non-contact detection of explosives for homeland security and environmental safety [8], a variety of spectroscopic technologies have been employed to detect trace quantities of explosives; for example, terahertz $(\mathrm{THz})$ spectroscopy $[9,10]$, laser induced breakdown spectroscopy (LIBS) [11-16], Raman spectroscopy [17-22], ion mobility spectrometry (IMS) [23-26], nuclear magnetic resonance (NMR) [27-30], nuclear quadrupole resonance (NQR) [31-33], laser-induced thermal emissions (LITE) [34,35], infrared (IR) spectroscopy [36-38], mass spectrometry [39-46], optical emission spectroscopy (OES) $[47,48]$, photo-thermal infrared 
imaging spectroscopy (PT-IRIS) [49-51], photoacoustic techniques [52-54], FT-FIR spectroscopy [55], microwave [56], and millimeter-wave [57], etc. Various electromagnetic radiations such as X-ray [58] and $\gamma$ rays [59] have also been employed in explosive detection. Each one of these techniques, however, has some specific limitations.

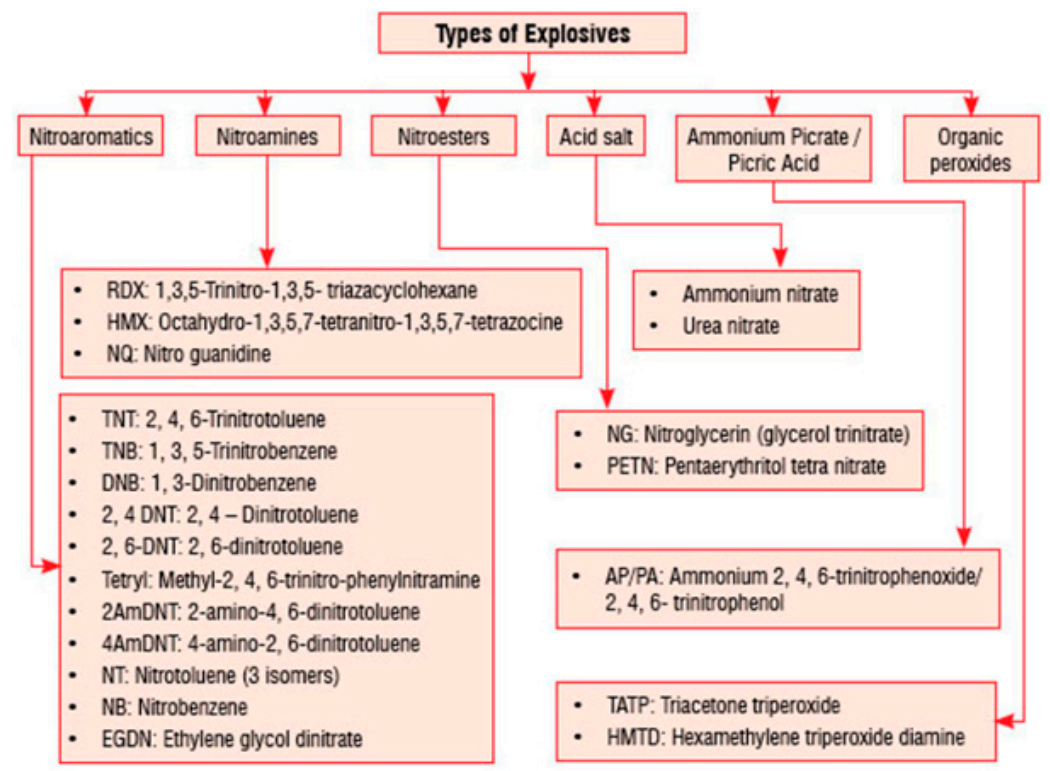

Figure 1. Classification of commonly used explosives.

The applications of spectroscopy-based methods for trace explosives detection has progressed significantly in the past several years. The purpose of this review is to summarize the applications of terahertz spectroscopy, laser-induced breakdown spectroscopy, Raman spectroscopy, and ion mobility spectroscopy for the detection of explosives, and summarize future trends in their development.

\section{Terahertz Spectroscopy}

$\mathrm{THz}$ spectroscopy, with the electromagnetic radiation in the frequency range of $0.1-10 \mathrm{THz}$, can be used to detect different kinds of physical phenomena, such as rotation and vibration transitions for molecules, collective vibration or torsion modes for condensed-phase materials [60]. Electromagnetic spectrum in the THz range for different applications is schematically illustrated in Figure 2 [61].

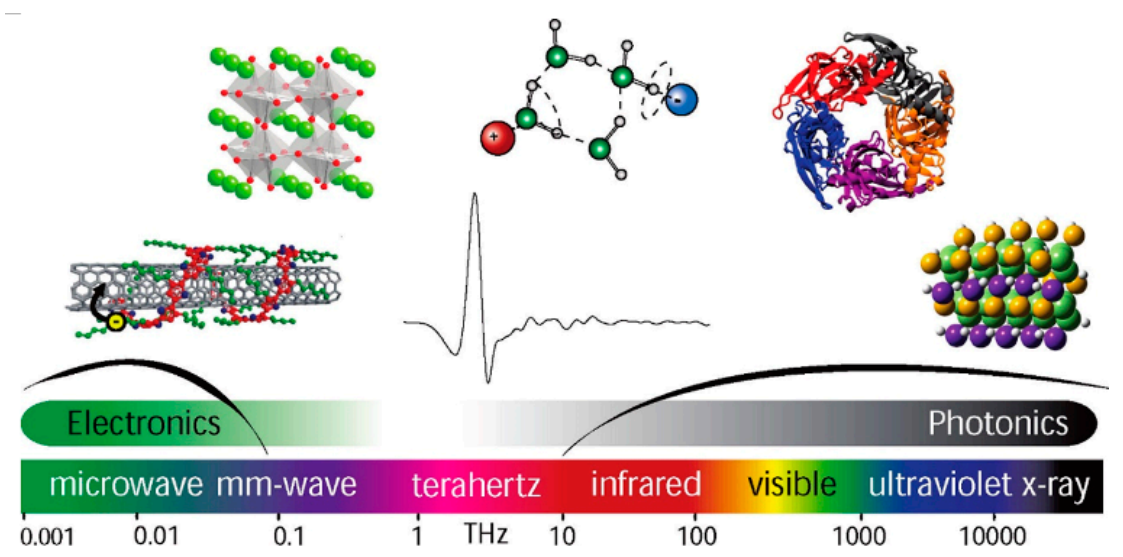

Figure 2. Electromagnetic spectrum in the $\mathrm{THz}$ range, with images highlighting the wide variety of molecules, materials, and phenomena that can be explored using $\mathrm{THz}$ spectroscopy. Adapted from [61], with permission from (c) 2011 American Chemical Society. 
The THz technology has the following advantages: it can transmit through a lot of common barrier materials, including packaging, plastics, paper, clothing, and ceramics, etc. These advantages make it possible to develop non-intrusive techniques that can detect hidden explosives. The lower related photon energy range is considered to be biologically safe, so the target being scanned is free from destructive photoionization. Explosives, drugs, and other biologics have unique absorption characteristics in the terahertz frequency range. [62-64] These spectral fingerprints are collectively due to the intermolecular and intramolecular vibrations $[65,66]$. The large-amplitude vibration modes detected in $\mathrm{THz}$ spectroscopy provide an in-depth understanding of the molecular structure dynamics by directly interrogating the motions responsible for conformational isomerization. Because of the delocalization property, the low frequency vibration mode is strongly influenced by the size and long-range order of molecules.

Terahertz time domain spectroscopy (THz-TDS) can determine the complex permittivity of various specimen in a common frequency band of $0.2-3 \mathrm{THz}$, and upper frequencies can be reached with ultra-short laser pulses $[61,67]$. The THz electromagnetic radiation produced by the emitter can be detected by a receiver. The THz-TDS results relate to the real-time detection of the electric field vector of the $\mathrm{THz}$ electromagnetic wave after the transmission through the sample compartment [68]. A generic schematic of the TDS device is shown in Figure 3. The laser pulse is divided into the pump beam and probe beam by the splitter. The pump pulse is excited terahertz pulses that pass by the GaAs photoconductive antenna. After passing through the sample, the terahertz beam with the information of the sample then combine with the probe beam. The obtained weak signal is finally amplified by a lock-in amplifier and collected by a computer for final processing [60].

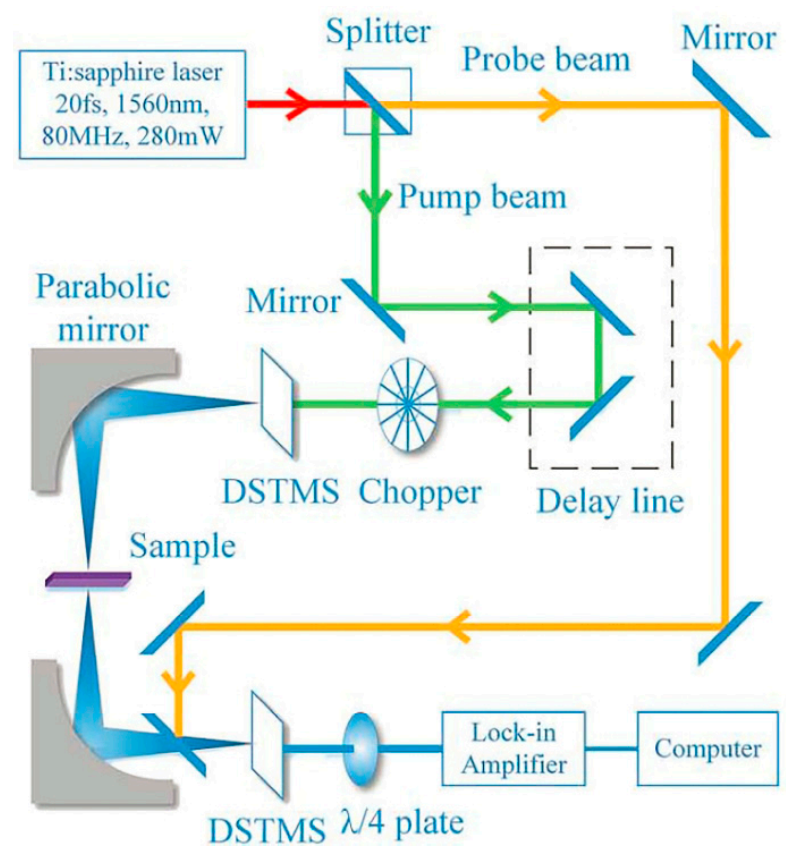

Figure 3. Schematic diagram of the transmission THz-TDS system. Adapted from [60], with permission from (c) 2016 Taylor \& Francis.

Sleiman et al. measured the absorption spectra of cyclotrimethylenetrinitramine (RDX), pentaerythritol tetranitrate (PETN), and their mixtures by THz-TDS. The samples were prepared by mixing pure explosives powder with polyethylene (PE). Preventing the overlapping of important spectral lines is a challenge for fingerprint inspection. A series of partial least squares regression models were built to predict the PETN concentrations in mixture samples. Moreover, when the original $0.2-3 \mathrm{THz}\left(6-100 \mathrm{~cm}^{-1}\right)$ spectral band was reduced to $1.8-3 \mathrm{THz}\left(60-100 \mathrm{~cm}^{-1}\right)$, the remarkably overlapping phenomenon of the spectral frequency band could be found. Furthermore, they revealed 
and identified specific explosives by applying partial least squares discriminant analysis to the absorbance $\mathrm{THz}$ images, and classifying each pixel as RDX, PETN, or RDX/PETN mixture. The identification and classification of explosives were successfully realized [69-71].

Trzcinski et al. reported the experimental results of the absorption spectra for RDX, PETN, and HMX by comparing with the absorption of their simulants using the THz-TDS system in the range of 0.1-3.0 THz. The samples contained 10\% explosives and 90\% Teflon. The absorbance peaks of all hazardous substances are identical in their properties, and their shapes are very similar. The oxidant measurement results show that $\mathrm{THz}$ measurement can be used not only for explosives detection but also for hazardous materials detection [72].

Pierno et al. obtained the terahertz spectra database of concealed PETN, RDX, TNT, and Semtex by common packaging materials. The sample in the form of polycrystalline was used without polypurification and diluted with polytetrafluoroethylene. The recorded terahertz spectrum has sufficient signal-to-noise ratio to identify hidden explosives. The detection limits for TNT is about $2 \%$ concentration by mass using broadband THz-TDS [66]. In another research, the samples of TNT, PETN, and RDX were prepared as $1 \mathrm{mg} / \mathrm{mL}$ solutions in methanol and characterized by THz-DS. The test results indicated that each temporal signal was distinctly different in intensity and shape, which showed the unique characteristics of the identified compounds [73]. The terahertz spectra of pure RDX, HMX, PETN, and their mixtures were also detected by using the TDS system at the transmission and reflection modes, the incident angle $r$ was about $45 \circ$ and the adopted distance was between stand-off with close to normal incidence with 30 and $40 \mathrm{~cm}$. The absorbance peak value of all substances was related to the characteristics of reflectance [74].

Reflection terahertz time-domain spectroscopy of nitramine explosives (RDX and HMX) were conducted in the range of $0.3-3 \mathrm{THz}$. Samples were prepared by pressing pure explosives that did not contain any additional binder or additives. The primary absorption peaks located at $0.84,1.08,1.50$, 1.92, and $2.30 \mathrm{THz}$ for RDX, and at 1.75, 2.50, and $2.90 \mathrm{THz}$ for HMX, are shown in Figure 4. RDX and HMX had completely different spectra, which were beneficial to distinguish them [75].

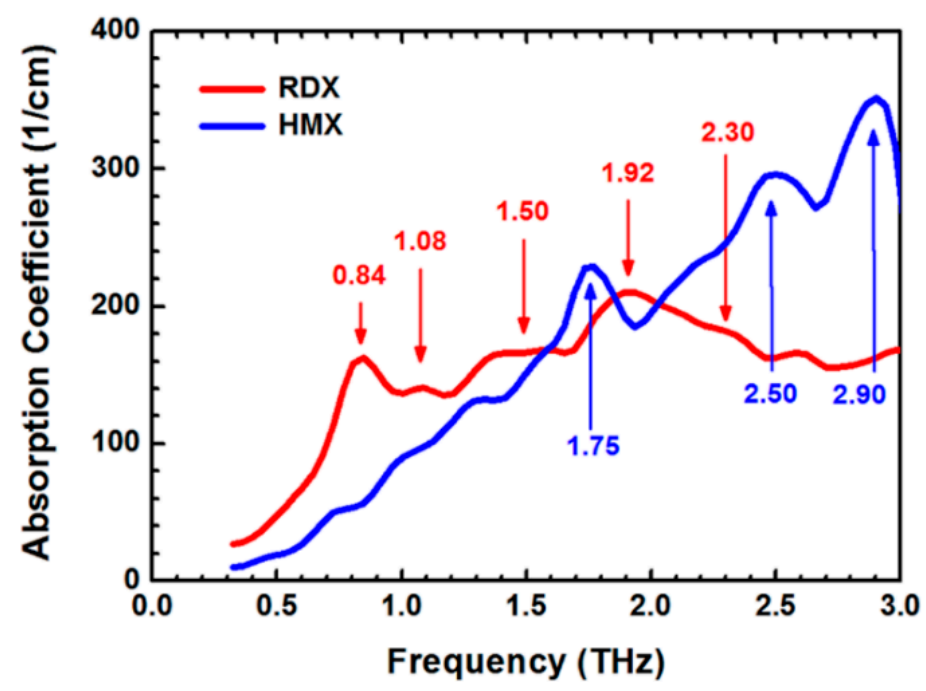

Figure 4. The absorption coefficient spectra of cyclotrimethylenetrinitramine (RDX) and HMX. Adapted from [75], with permission from @ 2014 American Institute of Physics.

For the purpose of providing references for the identification of high nitrogen compounds, Huang et al. measured terahertz spectra of 5-aminotetrazolium nitrate (5-ATN), hydrazine bistetrazolium-(4-methyl-1,5-diaminotetrazolium) (BMDATHBT), oxidizers $\left(\mathrm{SrNO}_{3}, \mathrm{KClO}_{3}, \mathrm{KClO}_{4}\right)$, and mixtures in the range of $0.5-2.0 \mathrm{THz}$ by using THz-TDS [76]. Theory calculations were also conducted by using the first principles method on the basis of density function theory (DFT) and the normal vibration modes of the crystal cells were performed by $\mathrm{Dmol}^{3}$. The measured and calculated 
resonance positions of these compounds are shown in Table 1 . The two vibrating peaks for the 5-ATN/SrNO 3 mixtures located at $0.72 \mathrm{THz}$ and $1.23 \mathrm{THz}$ are caused by 5-ATN and another peak at 1.80 is due to $5-\mathrm{ATN}$ and $\mathrm{SrNO}_{3}$. Comparably, the vibration peaks at $1.55 \mathrm{THz}$ and $1.67 \mathrm{THz}$ are due to BMDATHBT while $\mathrm{SrNO}_{3}$ accounts for the peak at $1.80 \mathrm{THz}$ for the BMDATHBT/SrNO 3 composites. In other research, they also measured the absorption coefficient of $2,2^{\prime}, 4,4^{\prime}, 6,6^{\prime}$-hexanitrostillbene (HNS) with THz-TDS and Fourier-transform infrared spectroscopy (FTIR). The results showed that the characteristic peaks could be found at $1.7 \mathrm{THz}$ and $3.1 \mathrm{THz}$. Both theoretical calculations and experimental results show that HNS has distinct characteristic peaks [77].

Table 1. Absorption peaks of nitrogen compounds, oxidizers, and mixtures.

\begin{tabular}{ccc}
\hline Compound & Measured Resonance/THz & Theoretical Resonance/THz \\
\hline $5-\mathrm{ATN}$ & $0.73,1.23,1.79$ & $1.12,1.66$ \\
$\mathrm{BMDATHBT}_{\mathrm{SrNO}}$ & $1.50,1.68$ & $1.48,1.70$ \\
$5-\mathrm{ATN}_{3} \mathrm{SrNO}_{3}$ & 1.80 & 1.72 \\
$\mathrm{BMDATHBT} / \mathrm{SrNO}_{3}$ & $0.72,1.23,1.80$ & - \\
$\mathrm{KClO}_{3}$ & $1.55,1.67,1.80$ & - \\
$\mathrm{KClO}_{3} / \mathrm{Al} / \mathrm{S}$ & 2.38 & 2.40 \\
$\mathrm{KClO}_{4}$ & 2.35 & - \\
$\mathrm{KClO}_{4} / \mathrm{Al} / \mathrm{S}$ & $2.00,2.17$ & $2.00,2.20$ \\
\hline
\end{tabular}

The characteristic THz-TDS absorption peaks of insensitive energetic material 2,6-diamino3,5-dinitropyrazine-1-oxide (LLM-105) appeared in 1.27, 1.59, 2.00, 2.08, 2.20, and 2.29 THz. The DFT simulation results were in good agreement with the experimental results, with the exception of the 2.29 THz peak, which may be due to the lattice vibration or other reasons [78]. They also found the characteristic peaks for 1,1-diamino-2,2-dintroethylene (FOX-7) located at 1.59 and 2.12 THz [79]. For RDX, five main absorption peaks were located around 0.82, 1.05, 1.50, 1.92, and 2.20 THz, which agreed well with Choi's results [75,80]. A subsequent study conducted by Guo et al., also demonstrated the use of THz-TDS to detect hexanitrohexaazaisowur-tzitane ( $\varepsilon$-HNIW and $\gamma$-HNIW) in the $0.2-2.5 \mathrm{THz}$ region. For $\varepsilon$-HNIW, the obvious absorption peaks could be found at $0.99,1.32,1.43$, and $2.08 \mathrm{THz}$. For $\gamma$-HNIW, the primary absorption peaks appeared at $1.05,1.52$, and $1.90 \mathrm{THz}[81]$.

Palka et al. measured the $\mathrm{THz}$ absorption spectra of six novel energetic materials: SAZ (azotetrazolatepentahydrat), AAZ (diammonium azotetrazolate), GUAZ (guanidinium azotetrazolate), TAGAZ (triamino-guanidiniumazo-tetrazolate), HNIW and TEX (tetraoxadinitroisowurtzitane) by using THz-TDS system [64]. All the materials were pressed into pellets for transmission investigations by mixing with PE powder, which is highly transparent in the THz region. The characteristic peaks of these explosives appeared in the range of $0.8-3 \mathrm{THz}$ in room temperature. The absorption peaks for SAZ were at 1.34, 1.81, 2.35, 2.57, 2.75, and $2.92 \mathrm{THz}$. There are five absorption peaks for AAZ at $1.76,2.40,2.55,2.71$, and $2.86 \mathrm{THz}$. GUAZ could be distinguished by the peak at 1.38, 2.01, 2.31, 2.55, 2.84, and 2.91 THz. TAGAZ had the feature peaks at 1.10, 1.46, 1.67, 2.12, 2.25, 2.38, and 2.96 THz. The characteristic peaks of TEX could be found at 1.71, 2.33, 2.53, and $2.91 \mathrm{THz}$. The absorption peaks for HNIW $(0.84,1.45,2.28$, and $2.77 \mathrm{THz})$ are different than Guo's results [81], which is due to the different crystalline forms of HNIW.

Choi et al. presented experimental results regarding principal interests and critical factors in the detection of explosive compounds by using THz-TDS. THz spectra of Composition B-3 and Pentolite, and suggested a novel signal processing method for in situ compound explosives detection [82]. Their signal processing procedure indicated that significant decrease was about $22.7 \%$ for Composition B-3 and $48.8 \%$ for Pentolite in noisy and humid environments.

Chrzanowski et al. applied THz-TDS to detect explosive liquids and liquid mixtures in analogy [83]. These explosive liquids can be significantly distinguished from each other on the 
basis of the refraction index in the lower $\mathrm{THz}$ region or by means of the absorption coefficient at a higher $\mathrm{THz}$ frequency range $(1 \mathrm{THz})$.

Puc et al. studied the influence of different backgrounds for the spectral features of different explosive simulants by using THz-TDS [84]. Combined with the organic-crystal-based terahertz time-domain system and the spectral peak analysis method, the hidden simulants can be quickly detected and identified in the frequency region of 1.5 to $4.0 \mathrm{THz}$.

\section{Laser-Induced Breakdown Spectroscopy}

LIBS is an elemental and molecular fragment analysis and detection technology based on emission spectrometry and the laser shifts the emission from atom and molecule for detection [85]. During the last few years, the laser based technique has attracted a lot of attention for the detection of energetic compounds [86-89]. LIBS has been successfully applied to the analysis of elements and small molecular fragments in various materials. It is one of the potential technologies that can be used for explosive detection for the reasons of non-contact, rapid response, high sensitivity, real-time and multi-element detection characteristics. It has been employed for identification of explosive residues, chemical and biological agents on different surfaces such as polymers, and metals, etc. [90,91]. The main physical and chemical processes involved in LIBS are demonstrated in Figure 5 with reference to analysis of a solid target in air [92]. The analyte was first ablated, then atomized, and finally ionized to produce a plasma plume.

\section{Plasma lifetime schematics}

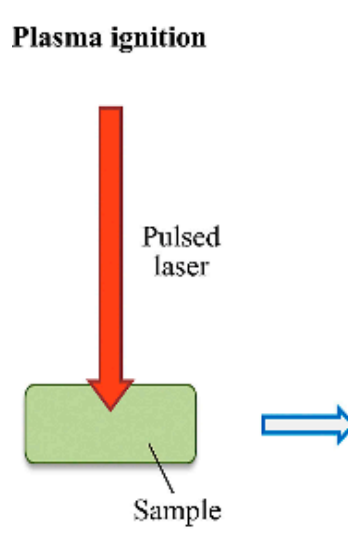

(a)

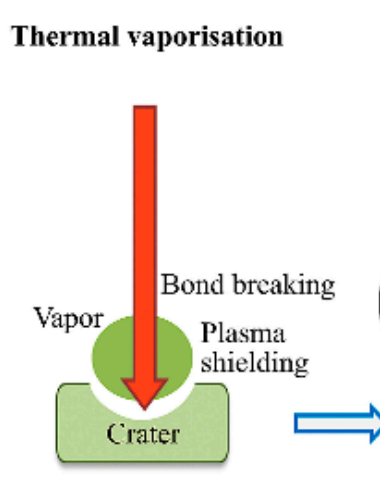

(b)
Plasma expansion

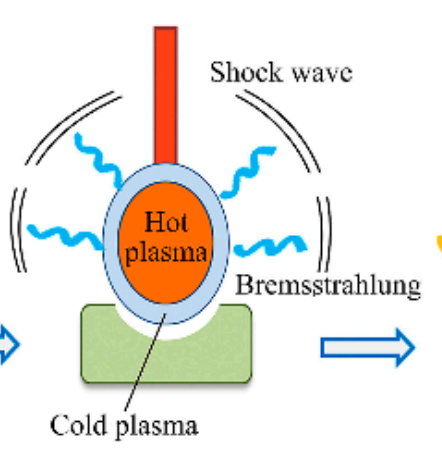

(c)

\section{Element specific emission}

Figure 5. Main steps in the laser pulse/material interaction resulting in the generation of laser induced breakdown spectroscopy (LIBS) emission signals. (a) Plasma ignition; (b) thermal vaporization; (c) plasma expansion; (d) element specific emission. Adapted from [92], with permission from (C) 2017 Elsevier.

LIBS has shown effective and promising results in the identification of explosive residues, the classification of polymers, and the analysis of complex biomaterials. It has been proven to be a real-time and effective chemical detection and analysis tool for the residue of energetic materials and explosives [93-96]. A typical schematic diagram of the LIBS experimental setup is shown in Figure 6 [97]. 


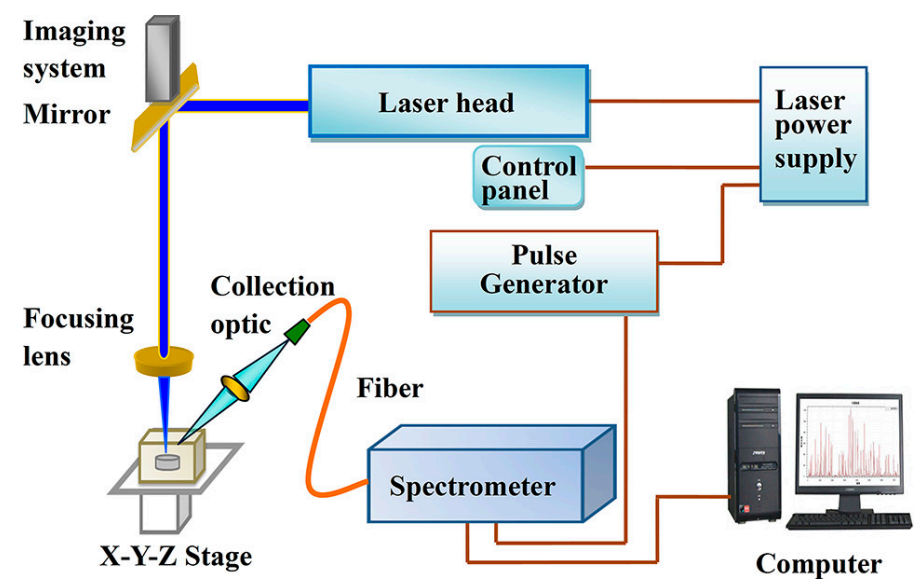

Figure 6. Schematic diagram of the LIBS experimental setup. Adapted from [97], with permission from (C) 2018 American Chemical Society.

Myakalwar et al. measured the spectra of HMX, NTO, PETN, RDX, and TNT on their LIBS system, as shown in Figure 7 [98]. The emission peaks were associated with $\mathrm{C}(247.8 \mathrm{~nm}), \mathrm{Mg}(279.5,280.3 \mathrm{~nm})$, $\mathrm{Ca}(393.3,396.8,422.7 \mathrm{~nm}), \mathrm{H}(656.3 \mathrm{~nm}), \mathrm{N}(742.4,744.3,746.9,818.4,818.8,821.6,824.2 \mathrm{~nm}), \mathrm{O}(777.2$, $777.4,794.8,822.2,822.7,844.6,868.1 \mathrm{~nm})$ and $\mathrm{Na}(589,589.6 \mathrm{~nm})$. Obviously, the peak with the highest intensity located at $777.3 \mathrm{~nm}$ corresponds to oxygen; the second strongest peak was found at $388.3 \mathrm{~nm}$ for $\mathrm{CN}$, which was accompanied by the $\mathrm{C}_{2}$ peaks, indicating the production of organic molecules.

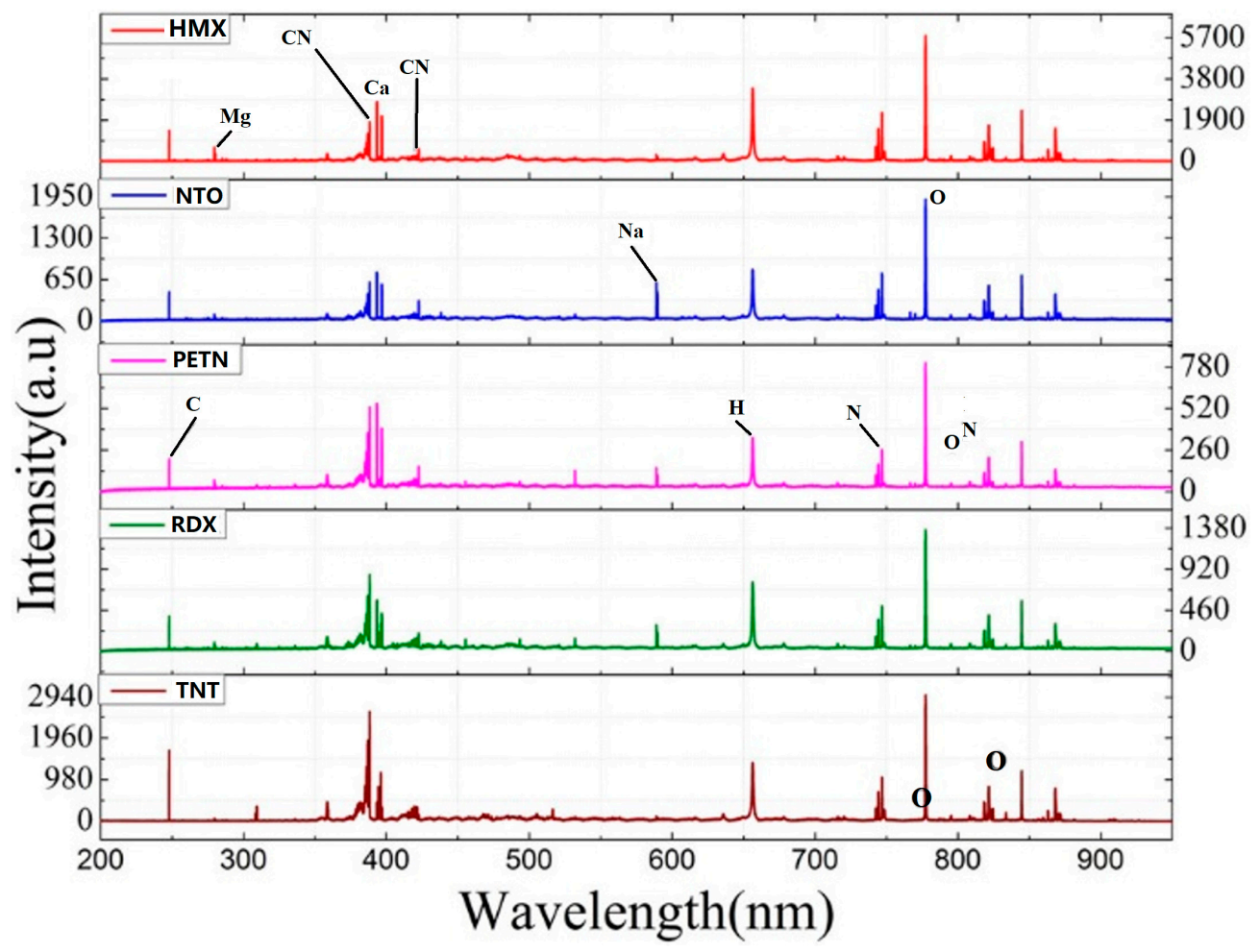

Figure 7. Representative LIBS spectra of typical explosives. Adapted from [98], with permission from (C) 2015 Springer Nature.

Yang et al. performed IR-LIBS studies for ammonium perchlorate (AP), ammonium nitrate (AN), and ammonium sulfate (AS) samples under air and nitrogen atmospheric conditions. These three samples are commonly used as oxidants in explosives, showing obvious infrared emission characteristics from target molecules in the range of 4-12 $\mu \mathrm{m}$. They also conducted the first study of 
mid infrared (MIR) LIBS of ammonium carbonate (AC). AC had distinct molecules/molecular debris infrared emission characteristics between 4 and $12 \mu \mathrm{m}$. The main emission peak near $4.4 \mu \mathrm{m}$ could be attributed to the $\mathrm{CO}_{2}$ emission, which is caused by the sputtering carbon atom oxidation in the sample [99].

By using fs and ns pulses, Rao et al. recorded the laser-induced breakdown spectra of several explosive compounds (nitroimidazoles) in air and argon environments. Dominant atomic (C, H, N and $\mathrm{O})$ and molecular $\left(\mathrm{CN}, \mathrm{C}_{2}\right.$ and $\mathrm{NH}$ ) and emission lines were recognized [90]. The emission peak of $\mathrm{CN}$ was dominant in the air, while the emission characteristics of $\mathrm{C}_{2}$ were significant in the LIB spectra obtained in argon atmosphere.

The emission spectra from fs and ns laser-induced plasmas of nitrotriazolone (NTO), RDX, and HMX have been reported [100]. Their elemental and molecular characteristic spectra were compared. C and CN peaks exist in the LIBS spectra, which confirmed the characteristics of high energetic materials. Table 2 lists all the atomic and molecular peaks observed for the three explosives in the fs and ns LIBS spectra. Compared with the ns spectra, some of the Nitrogen peaks obtained in the fs LIBS spectra were weaker in intensity. The presence of an additional CN peak (at $385.01 \mathrm{~nm}$ ) in the fs spectra was identified for all samples while in the ns spectra the peak was covered by the noise.

Table 2. List of various atomic and molecular peaks in the LIBS spectra of NTO, RDX, and HMX obtained using fs and ns pulses.

\begin{tabular}{|c|c|c|c|c|c|c|c|}
\hline \multirow{2}{*}{ Peak/nm } & \multirow{2}{*}{ Species } & \multicolumn{2}{|c|}{ RDX } & \multicolumn{2}{|c|}{ HMX } & \multicolumn{2}{|c|}{ NTO } \\
\hline & & ns & fs & ns & fs & ns & fs \\
\hline 247.82 & $\mathrm{C}$ & * & * & * & $*$ & * & * \\
\hline $279.49,280.21,285.10$ & $\mathrm{Mg}$ & * & $*$ & * & $*$ & * & * \\
\hline 385.01 & $\mathrm{CN}$ & \# & $*$ & \# & $*$ & $\#$ & * \\
\hline 385.40 & $\mathrm{CN}$ & * & $*$ & * & * & * & * \\
\hline 386.16 & $\mathrm{CN}$ & * & $*$ & $*$ & $*$ & * & * \\
\hline 387.07 & $\mathrm{CN}$ & * & $*$ & $*$ & $*$ & * & * \\
\hline 388.28 & $\mathrm{CN}$ & * & $*$ & * & $*$ & * & * \\
\hline $393.25,396.77$ & $\mathrm{Ca}$ & * & * & $*$ & $*$ & * & * \\
\hline $394.4,396.15$ & $\mathrm{Al}$ & * & $*$ & * & $*$ & * & * \\
\hline $588.89,589.50$ & $\mathrm{Na}$ & * & * & * & * & * & * \\
\hline 656.2 & $\mathrm{H}$ & * & * & * & * & * & $*$ \\
\hline $742.2,744.1,746.8$ & $\mathrm{~N}$ & $* *$ & * & $* *$ & * & $* *$ & * \\
\hline 777.20 & $\mathrm{O}$ (triplet) & $*$ & * & * & * & * & * \\
\hline $818.34,818.64,821.50,822.35$ & $\mathrm{~N}$ & * & * & * & * & * & * \\
\hline $\begin{array}{c}824.22,859.5,856.74,862.9,865.66 \\
868.03,870.25,871.10,870.74\end{array}$ & $\mathrm{~N}$ & $* *$ & * & $* *$ & * & $* *$ & * \\
\hline 844.55 & $\mathrm{O}$ & * & * & * & * & * & * \\
\hline $867.80,868.80$ & $\mathrm{~N}$ & * & $*$ & * & $*$ & * & * \\
\hline
\end{tabular}

* Indicates peak present, ${ }^{* *}$ indicates higher magnitude, $\#$ indicates buried in the noise.

LIBS spectral characteristic lines for NTO, RDX, and TNT samples were obtained in air, nitrogen, and argon atmospheres by Sreedhar et al., as shown in Table 3 [101]. A slight change was observed depending on the nature of the sample and the surrounding atmosphere. The intensity of $C(247.8 \mathrm{~nm})$ and $\mathrm{H}_{\alpha}(656.2 \mathrm{~nm})$ peaks were strong in the argon condition for all the explosives. The TNT sample had a strong peak at $C_{2}(516.47 \mathrm{~nm})$ in an argon atmosphere. Compared with the spectra in argon, the $\mathrm{CN}$ violet band for $\Delta v=0$ transitions in the spectral region of $385-388 \mathrm{~nm}$ was found to be strong in nitrogen and air conditions. 
Table 3. Description of elemental and molecular peaks obtained in three atmospheres for NTO, RDX, and TNT samples.

\begin{tabular}{|c|c|c|c|c|c|c|c|c|c|c|}
\hline \multirow{2}{*}{ Species } & \multirow{2}{*}{ Peaks/nm } & \multicolumn{3}{|c|}{ NTO } & \multicolumn{3}{|c|}{ RDX } & \multicolumn{3}{|c|}{ TNT } \\
\hline & & Air & $\mathbf{N}_{2}$ & Ar & Air & $\mathbf{N}_{2}$ & Ar & Air & $\mathbf{N}_{2}$ & Ar \\
\hline $\mathrm{C}$ & 247.82 & * & * & ${ }^{*} \mathrm{~B}$ & * & * & ${ }^{*} \mathrm{~B}$ & * & * & ${ }^{*} \mathrm{~B}$ \\
\hline $\mathrm{Ca}$ & $393.35,396.83,422.67$ & * & * & $*$ & * & * & $*$ & - & - & - \\
\hline $\mathrm{CN}-(\Delta v=+1)$ & 359.02 & * & * & * & * & * & ${ }^{*} \mathrm{~L}$ & * & * & ${ }^{*} \mathrm{~L}$ \\
\hline $\mathrm{CN}-(\Delta v=0)$ & $\begin{array}{c}388.28,387.07,386.16,385.40 \\
385.01\end{array}$ & * & ${ }^{*} \mathrm{~B}$ & * & * & $* \mathrm{~B}$ & * & * & ${ }^{*} \mathrm{~B}$ & * \\
\hline $\mathrm{CN}-(\Delta v=-1)$ & $421.50,419.63,418.03,416.78$ & * & * & * & * & * & ${ }^{*} \mathrm{~L}$ & * & * & * \\
\hline $\mathrm{C}_{2}-(\Delta v=+1)$ & $473.63,471.50$ & - & - & - & - & - & - & * & ${ }^{*} \mathrm{~L}$ & * \\
\hline $\mathrm{C}_{2}-(\Delta v=0)$ & 516.47 & - & - & ${ }^{*} \mathrm{~L}$ & - & - & ${ }^{*} \mathrm{~L}$ & * & $*$ & ${ }^{*} \mathrm{~B}$ \\
\hline $\mathrm{Na}$ & $588.89,589.50$ & * & $*$ & $*$ & * & * & * & - & - & - \\
\hline $\mathrm{H} \alpha$ & 656.2 & * & * & ${ }^{*} \mathrm{~B}$ & * & * & * & * & * & ${ }^{*} \mathrm{~B}$ \\
\hline $\mathrm{O}$ & $777.2,844.55$ & $* \mathrm{~B}$ & * & $*$ & $* \mathrm{~B}$ & * & * & $* \mathrm{~B}$ & * & * \\
\hline $\mathrm{N}$ & $821.50,822.35$ & $*$ & * & * & * & * & * & * & * & * \\
\hline $\mathrm{N}$ & $867.80,868.80$ & * & * & $*$ & * & * & * & * & * & * \\
\hline
\end{tabular}

* Indicates the presence of peak, - indicates the absence of peak, L refers to peak presence with lower intensity (or buried in the noise), B refers to peak presence with higher intensity among three atmospheres.

Rao et al. performed LIBS research on pyrazole, 1-nitropyrazole, 3-nitropyrazole, 3,4-dinitropyrazole and 1-methyl-3, 4,5 trinitro pyrazole [102,103]. CN molecular fragment bands in the ranges of $357-360 \mathrm{~nm}, 384-389 \mathrm{~nm}$ and $414-423 \mathrm{~nm}, \mathrm{C}_{2}$ Swan bands in the range of 460-475 nm, 510-520 nm and $550-565 \mathrm{~nm}$ were observed. They also employed LIBS to investigate some nitropyrazole molecules in air, nitrogen, and argon atmospheres. The LIBS data proved the existence of molecular emissions of cyanide $(\mathrm{CN})$ violet bands, diatomic carbon $\left(\mathrm{C}_{2}\right)$ Swan bands, and atomic emission lines of $\mathrm{C}, \mathrm{H}, \mathrm{O}$, and $\mathrm{N}$. The observed decay times and molecular emission intensities were related to the number of nitro groups, atmospheric nitrogen content, and molecular oxygen balance.

Delgado et al. performed the LIBS characterization of TNT and PETN in $\mathrm{N}_{2}$ and air atmospheres [104]. The results indicated that $C_{2}$ emission was strongly connected to the molecular structure as well as $\mathrm{CN}$ was the production of chemical reactions. In the $\mathrm{H}_{2}$ atmosphere, the results suggested that $\mathrm{H}_{2}$ might change the formation pathway of molecular fragments, thereby reducing the emission of $\mathrm{CN}$ and $\mathrm{C}_{2}$, and promoting the formation of $\mathrm{NH}, \mathrm{CH}$ and $\mathrm{OH}$. They have confirmed these results in an environment without air, where molecular fragment emissions were still very weak. This fact might be due to the reaction between $\mathrm{H}_{2}$ / other atomic species and molecular species of the plasma leading to dissociation of small fragments $\left(\mathrm{CN}, \mathrm{C}_{2}\right.$, et al.).

De Lucia et al. obtained time-resolved LIBS spectra of some polymers and RDX and compared the atomic emission intensities of each sample [105]. It could be seen from the observed trend of the emission intensity that the atomic emission intensity may be related to the chemical composition of the sample. The relationship between emission intensity and molecular structure was a key factor to distinguish different kinds of energetic materials by LIBS. In addition, the plasma emission spectra of aluminized RDX explosives were obtained in air and argon atmosphere using LIBS technology. The atomic bands of $\mathrm{Al}, \mathrm{C}, \mathrm{H}, \mathrm{N}$, and $\mathrm{O}$, and the molecular bands of $\mathrm{AlO}$ and $\mathrm{CN}$ have been determined. Aluminum and oxygen content in the plasma affected the produce mechanism of $\mathrm{AlO}$ and $\mathrm{CN}$ molecular bands [106].

Aromatic nitrocompounds (MNT, DNT and TNT), RDX, anthracene, 2,4-diaminotoluene (DAT), 4-methyl-3-nitroaniline (MNA), and pentaerythritol (PENT) have been characterized by LIBS [11]. To prevent the secondary ionization and to distinguish between the spectral contribution owing to air from that of the substance in the plasma produced in air, the emission characteristics from atomic lines (C at $247.9 \mathrm{~nm}, \mathrm{H}$ at $656.3 \mathrm{~nm}, \mathrm{~N}$ at $746.8 \mathrm{~nm}$ and $\mathrm{O}$ at $777.2 \mathrm{~nm}$ ), and molecular bands (CN at $388.3 \mathrm{~nm}$ and $\mathrm{C}_{2}$ at $516.5 \mathrm{~nm}$ ) have been researched in plasmas produced in air and in helium. 
As shown in Figure 8, significant differences in intensity distributions indicated that identification between compounds was possible.

The LIBS spectra of nitrogen-rich compounds, such as 5-aminotetrazoliumni-trate (HAT-NO3) and hydrazinebistetrazole (HBT), bis(2,2,2-trinitroethyl)-hydrazodicarboxylate (BTHC), RDX, TNT, melamine, sucrose, and l-glutamine were recorded. The emission intensities of the atoms and the intensity ratios of the constituent elements in the LIBS spectrum are related to the mole fraction and the stoichiometry of the molecules. Moreover, the oxygen content in the molecule affects the emission intensity of molecular fragments, such as C2 [107].

Recently, standoff (up to $\sim 2 \mathrm{~m}$ ) and remote $(\sim 8.5 \mathrm{~m}$ ) detection of new energetic compounds (nitroimidazoles and nitropyrazoles) were performed by using LIBS. Dominant spectral features of explosives $\left(\mathrm{C}, \mathrm{H}, \mathrm{N}, \mathrm{O}\right.$ atomic transitions and $\mathrm{CN}, \mathrm{C}_{2}, \mathrm{NH}$ molecular bands) were readily identified [108].
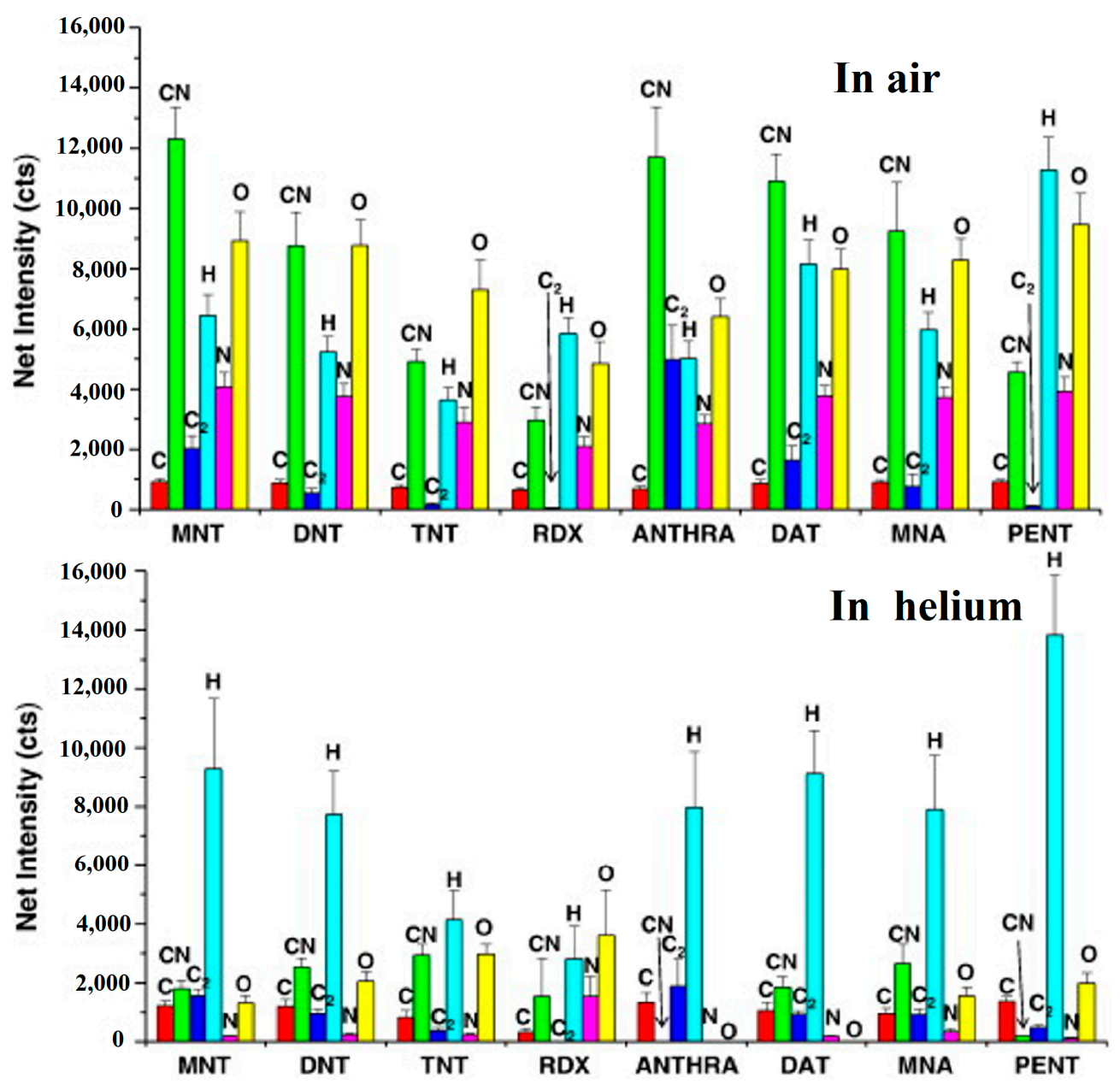

Figure 8. Net intensity of the LIBS signal in air and helium from several organic compounds. Adapted from [11], with permission from @ 2011 Elsevier.

\section{Raman Spectroscopy}

As a vibrational spectroscopy, Raman spectra involve information about the specific arrangement and interaction of the atoms forming the molecule. It can be used to reveal the molecular information of a sample at the micro meter scale in a non-destructive way. Figure 9 describes the Rayleigh and Raman scattering [109]. Different from IR spectroscopy, Raman spectra show less dependent on the size of the particle and nature of the background surface. Raman spectra of different molecules have 
their unique fingerprint characteristics, that means each spectrum has specific and unique feature bands that can be selected for recognition [110].

Due to the progress of instrument science, Raman spectroscopy technology is widely applied in various research fields, allowing scientists to extract new information from different samples. The information is highly molecularly specific and allows for a distinction between different types of explosives. The schematic of a Raman spectrometer is shown in Figure 10 [111]. After inducing by excitation laser shot on the sample, the Raman-scattered light of the sample was transferred to the spectrometer by using an optical fiber. The commonly used excitation laser sources are a $785 \mathrm{~nm}$ diode laser and $1064 \mathrm{~nm} \mathrm{Nd:YAG} \mathrm{laser.}$

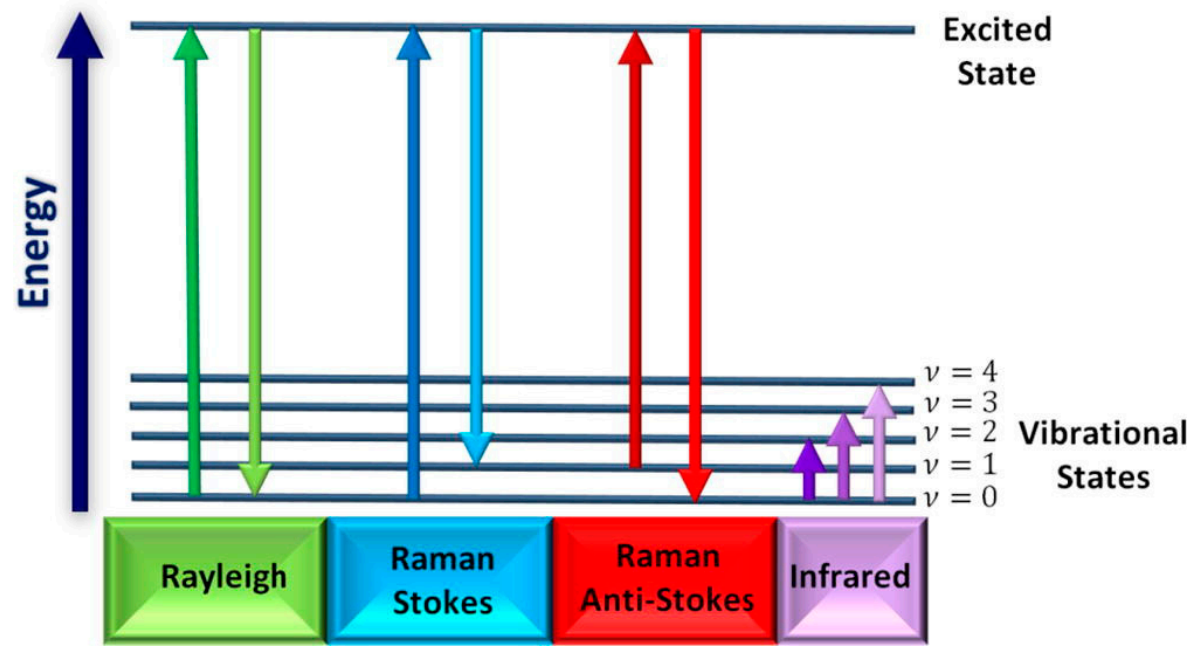

Figure 9. Modified energy diagram for Rayleigh and Raman scattering. Adapted from [109], with permission from (c) 2018 Elsevier.

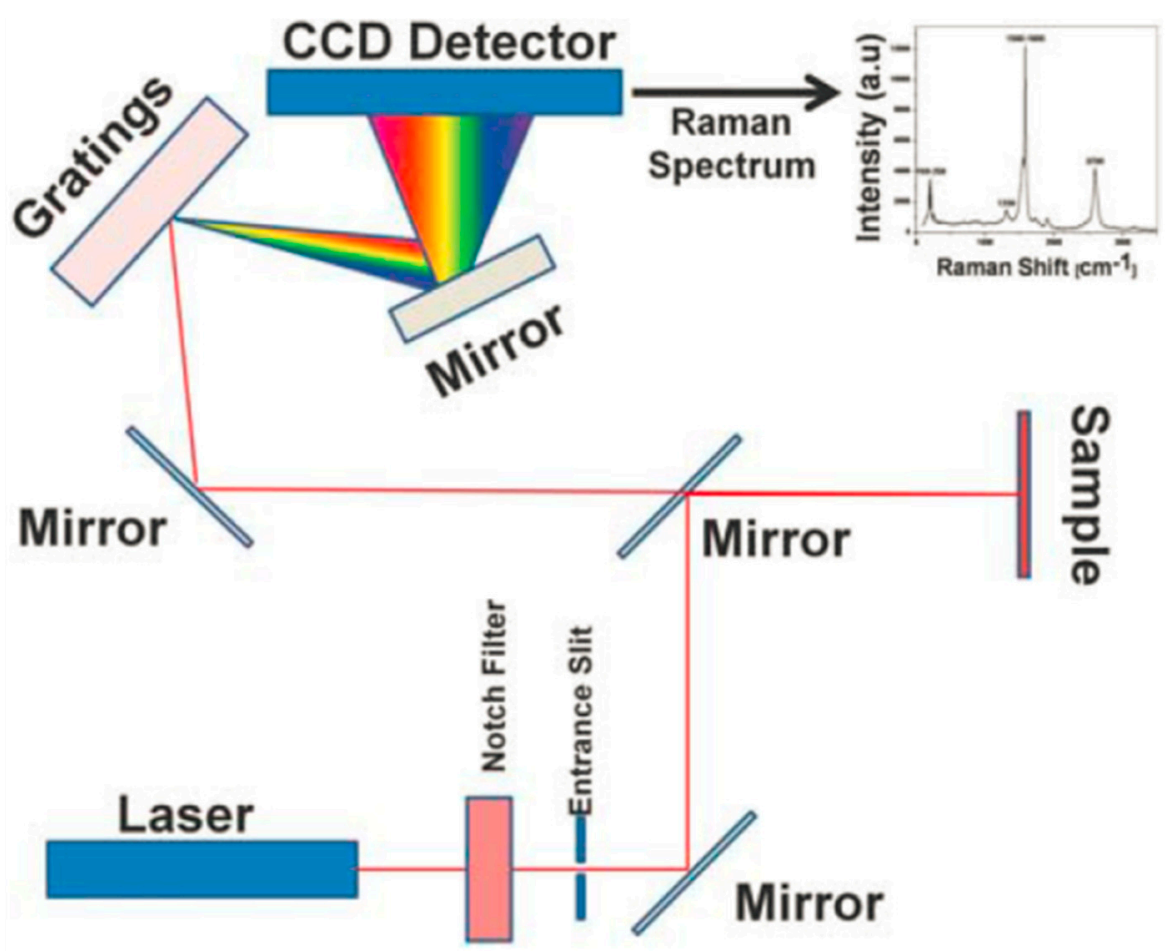

Figure 10. Schematic diagram of the Raman system. Adapted from [111], with permission from (C) 2017 Elsevier. 
The Raman spectra of PETN, RDX, TNT, and ethane-1,2-diyl dinitrate (EGDN) in the spectral Raman shift range of $250-2500 \mathrm{~cm}^{-1}$ were obtained by Almaviva et al., as shown in Figure 11 [112]. Comparing the Raman spectra of these explosives, it was found that these substances can be easily identified by their main spectral characteristics, with strong characteristic peaks in the spectral wavenumber range of $250-1800 \mathrm{~cm}^{-1}$.
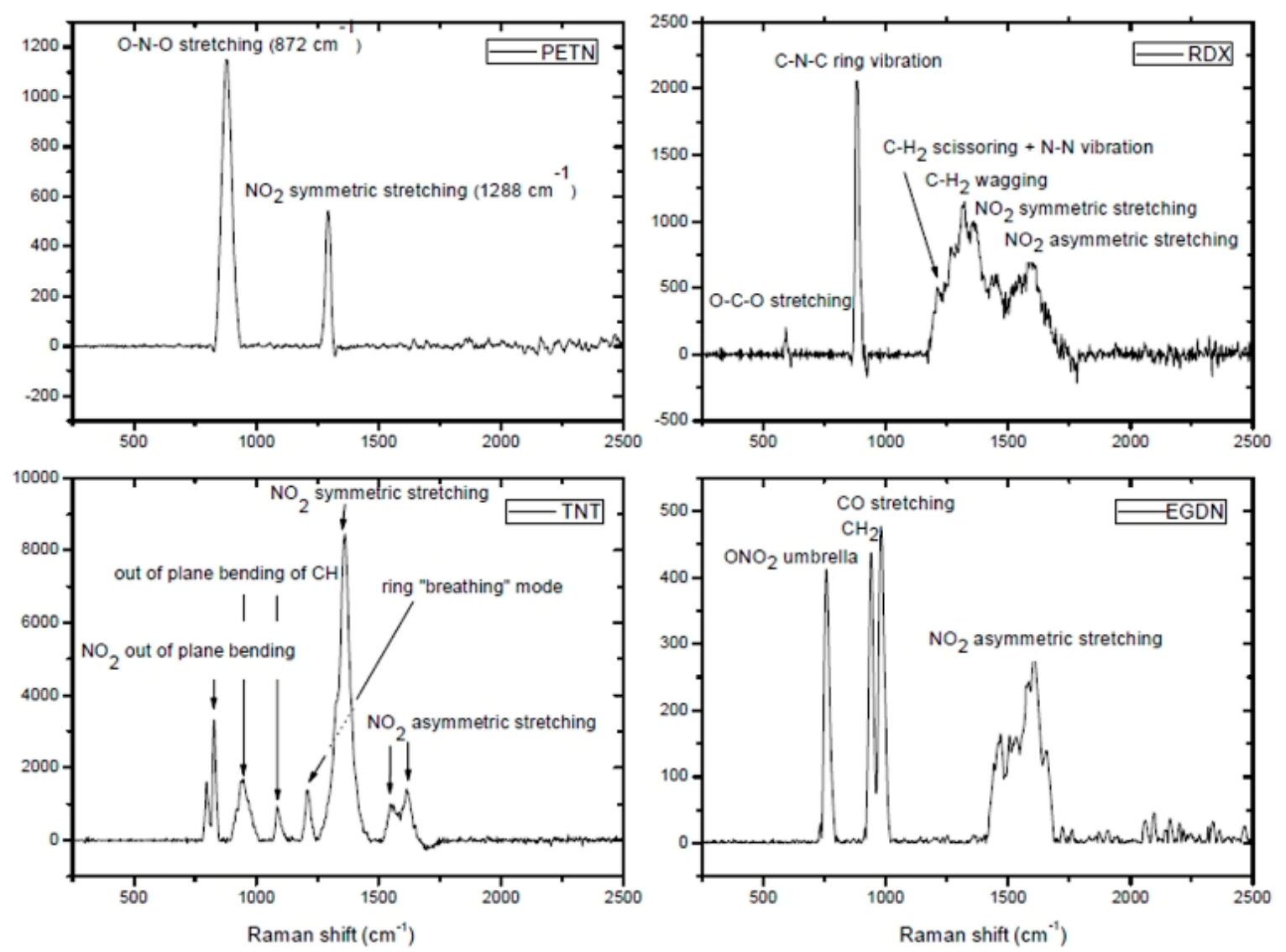

Figure 11. Surface-enhanced Raman spectra of PETN, RDX, TNT, and EGDN. Adapted from [112], with permission from @ 2012 SPIE.

Jin et al. performed an experiment by using the homemade Raman standoff spectroscopy system to detect different explosives [113]. Raman spectra of TNT, RDX, HMX, PETN, and triacetone triperoxide (TATP) over a long distance up to $54 \mathrm{~m}$ were successfully recorded for explosive identification. Most of the shapes of feature peaks were preserved relatively well, and the chemical information could be well recognized despite some missing information, including the shifts and loss of some peaks of the observed Raman signal.

In another research, the UV resonance Raman spectroscopy/differential Raman cross-sections of TNT, PETN, RDX, HMX, and AN in acetonitrile and water solutions were measured at 204-257 $\mathrm{nm}$. It was found that the spectral signal increases significantly with the decrease of excitation wavelength [114].

Hwang et al. measured the Raman spectra of representative energetic compounds (TNT, RDX, HMX, PETN, AN, NTO, HNIW, NQ, AND, AP, DMDNB, Tetryl, 2-DNT, and 4-ADNT) under the excitation wavelength of $514.5 \mathrm{~nm}, 632.7 \mathrm{~nm}$, and $785 \mathrm{~nm}$. Based on the measured spectral data, the relationship between the excitation wavelength, fluorescence effects, and their structure-property were revealed. The identification characteristics of different explosive compounds were obtained by principal component analysis [115]. 
Nuntawong et al. carried on the Raman detection directly on some points on the bulk explosive samples, the analysis results indicated that the Raman signals were relatively weak and uneven [116]. Figure 12 showed the obtained Raman spectra of the bulk explosives with corresponding fluorescence baselines. Despite the fluorescent peak intensities were quite high, medium peak intensities of nitrate due to a symmetric $\mathrm{N}-\mathrm{O}$ stretching were appeared at $1054 \mathrm{~cm}^{-1}$ for all the spectra.

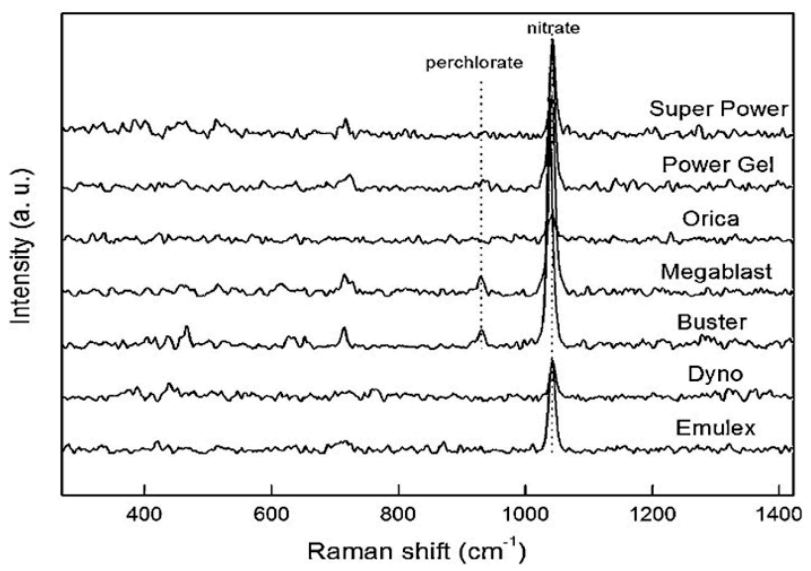

Figure 12. Raman spectra of the bulk volume of seven explosives. Adapted from [116], with permission from (C) 2013 Elsevier.

A new method using confocal Raman microscopy was adopted for the measurement and recognition of microscopic post-blast particles of explosives. The results showed that the explosive mixture based on the oxide salt can successfully identify unreacted particles by confocal Raman microscopy after the explosion. Nevertheless, it was impossible to detect non reactive particles after explosion for pure organic explosives through this method [117].

Zhang et al. obtained the Raman signal intensities of ammonium nitrate, potassium nitrate, and sodium nitrate in solid samples in a distance range from $2 \mathrm{~m}$ to $10 \mathrm{~m}$ [118]. The Raman spectra of these three samples look similar: each of them has a highest peak in the vicinity of $1050 \mathrm{~cm}-1$, small differences can serve as a "signature" for discriminating between them.

Recently, Hufziger et al. conducted an experiment by using a novel ultraviolet (UV) Raman standoff wide-field imaging spectrometer for detecting explosive residues [119]. The estimate detection limits of PETN and $\mathrm{NH}_{4} \mathrm{NO}_{3}$ is $1 \mathrm{mg} / \mathrm{cm}^{2}$ while the standoff distance is $2.3 \mathrm{~m}$.

Surface-enhanced Raman scattering (SERS) technology can enlarge intensities of the Raman signals by several orders while molecules were scattered at or near hot spots, making ultrasensitive detection of samples possible, even at the single-molecule level [120]. In a recent review, the recognition of explosives in different states was summarized, the potential of SERS for vapor detection of explosives through SERS sensors as chemical noses was shown, and the problems of perchlorate anion detection in water was reviewed [121]. Hakonen et al. discussed the possible use of SERS for convenient in-situ threat recognition and summed up existing SERS detection methods and substrates with a distinctive focus on ultra-sensitive real-time detection [122]. SERS technology could achieve the detection limit of $5 \mathrm{ppb}$ on a polished gold film substrate with the analysis time of $30 \mathrm{~s}$ for DNT. The main concepts, detection abilities, and prospects were discussed to guide homeland security and counter-terrorism.

Jamil et al. demonstrated a rapid and selective recognition of TNT by SERS using 6-aminohexanethiol (AHT) as a novel identification molecule [123]. AHT:TNT complex formation was verified by the development of a pink color and the emergence of new band near $500 \mathrm{~nm}$ in UV-vis spectrum. Solution Raman spectroscopy result also supported the AHT:TNT complex formation by obvious changes in the vibrational stretching of the AHT molecule between 2800 and $3000 \mathrm{~cm}^{-1}$. Their method also displayed excellent selectivity towards TNT over 2,4-DNT and picric acid. 
In a recent review, several detection strategies based on SERS for detecting different explosive compounds in different environments were summarized. The results indicated that explosives can be recognized in the ppb range in air as well as in the picomolar range in water. The majority of the SERS measurement procedures possess a preferable detection range compatible with applications [124].

Ultraviolet resonance Raman spectroscopy (UVRRS) has been used to examine nitro aromatic compounds (1,2-DNB, 1,3-DNB, 1,4-DNB, and TNT). The spectra showed remarkable resonance enhancement with laser wavelengths of $229 \mathrm{~nm}$ and $262 \mathrm{~nm}$. At these wavelengths, there was a good correlation between the magnitude of enhancement and the intensity of UV-Vis absorption. This change provided another way to identify the spectra of these related substances [125].

Yellampalle et al. proposed the concept of multiple-excitation-wavelength deep-ultraviolet resonance Raman technique (DUVRRS) for the trace detection of explosives [126]. Three explosives, ammonium nitrate (AN), ammonium nitrate/fuel oil (ANFO), and Watergel containing nitrates had a very distinctive characteristic nitrate band at $1042 \mathrm{~cm}^{-1}$ by using the $248 \mathrm{~nm}$ excitation wavelength, as shown in Figure 13. ANFO had an obvious frequency band at $1378 \mathrm{~cm}^{-1}$, probably caused by naphthalenic-type derivatives in fuel oil. Spectral features contained sufficient variation among the intensities of the bands in each spectrum. This ensured that the three spectra could be clearly distinguished.

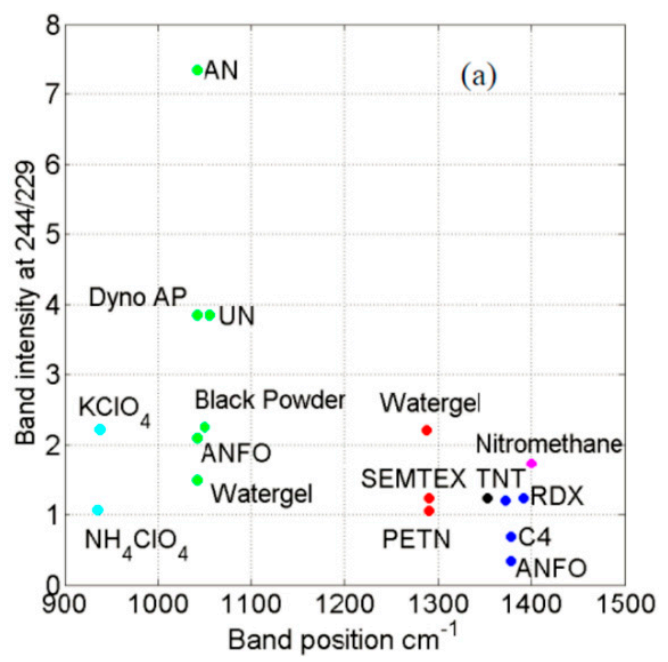

Figure 13. Dual-excitation-wavelength signatures of measured explosives. Adapted from [126], with permission from (c) 2013 SPIE.

\section{Ion Mobility Spectroscopy (IMS)}

IMS is a widely used method for rapid detection of explosives at airports around the world. It has been considered to be one of the best technologies to detect trace explosives because of its low detection limit, fast response, simplicity, and strong portability [6]. The disadvantages of IMS were limited linear dynamic range and relative poor resolution, which were due to a finite reservoir of charge and limited drift tubes. The principle of typical IMS instruments is depicted in Figure 14 [127]. The sample molecules are ionized with a corona discharge source or a radiation source. The ions then come into a field-free drift region driven by an electric gradient, where they finally drift toward a collector. The compounds are identified based on the time needed for ionized molecules to drift through the electric field.

Sivakumar et al. developed an ion mobility spectrometer to detect explosive species and reached a configuration providing good sensitivity with adequate resolution [128]. TNT and RDX were detected to less than $1 \mathrm{ppb}$ by volume levels in the vapor mode. The sensitivity was about $10 \mathrm{ng}$ for TNT and RDX and $50 \mathrm{ng}$ for PETN. 
Lee et al. analyzed five commonly used explosives (RDX, HMX, TNT, DNT, and PETN) by using ion mobility spectrometry-mass spectrometry (IMS-MS) [129] RDX $\cdot \mathrm{NO}_{3}{ }^{-}, \mathrm{TNT}^{-}, \mathrm{PETN} \cdot \mathrm{NO}_{3}{ }^{-}$, $\mathrm{HMX} \cdot \mathrm{NO}_{3}{ }^{-}$, and $\mathrm{DNT}^{-}$were detected and the average drift times were $6.93 \mathrm{~ms}, 10.20 \mathrm{~ms}, 9.15 \mathrm{~ms}$, $12.24 \mathrm{~ms}, 11.30 \mathrm{~ms}$, and $8.89 \mathrm{~ms}$, respectively. The detection limits were $0.1 \mathrm{ng}$ for RDX, $10 \mathrm{ng}$ for TNT, $0.5 \mathrm{ng}$ for PETN, $5.0 \mathrm{ng}$ for HMX, and $10 \mathrm{ng}$ for DNT. They proposed that different ionization sources might cause different results.

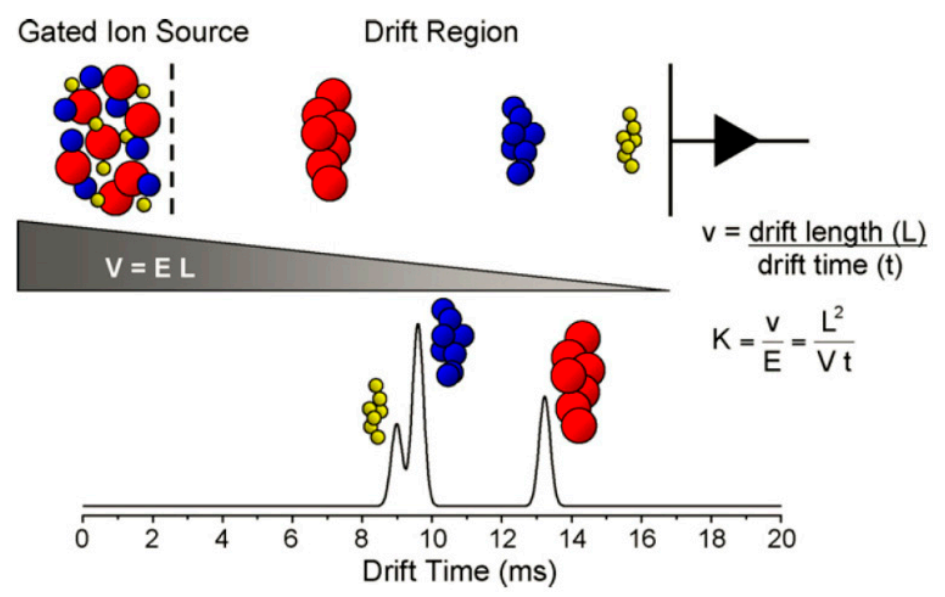

Figure 14. Principle of ion mobility spectroscopy. Adapted from [127], with permission from (C) 2007 Elsevier.

Langmeier et al. performed the detection of TNT and HMX with a new laser ion mobility spectrometer (LIMS); detection limits were $1 \mathrm{ng}$ for TNT and about $20 \mathrm{ng}$ for HMX [130]. The analysis of desorption curves allowed additional spectral features to be extracted, which could be used to distinguish substances with a similar drift time.

Tabrizchi et al. used IMS to detect explosives in the positive mode, and their results were demonstrated in Figure 15 [131]. Each explosive compound has a unique pattern and displays additional peaks that can be used to identify. The detecting limit for RDX, HMX, PETN, NTO, and TNT were about $1,10,40,1000$, and $1000 \mathrm{ng}$, respectively.

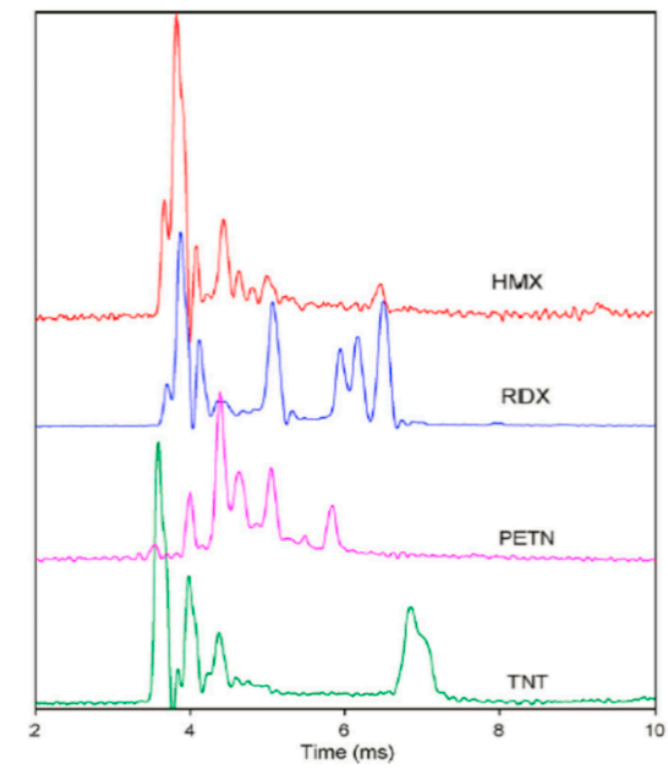

Figure 15. Positive ion mobility spectra of TNT, RDX, HMX, and PETN. Adapted from [131], with permission from (c) 2010 Elsevier. 
Hilton et al. analyzed ten kinds of commonly used explosives with a commercial electrospray ionization-high resolution ion mobility spectrometer (ESI-HRIMS) [132]. The obtained ion mobility spectra possessed a great deal of recognition information, as shown in Figure 16. They suggested that the high resolution instrument could produce quantitative or semi quantitative information on the explosive compounds of conventional explosives sample analysis.

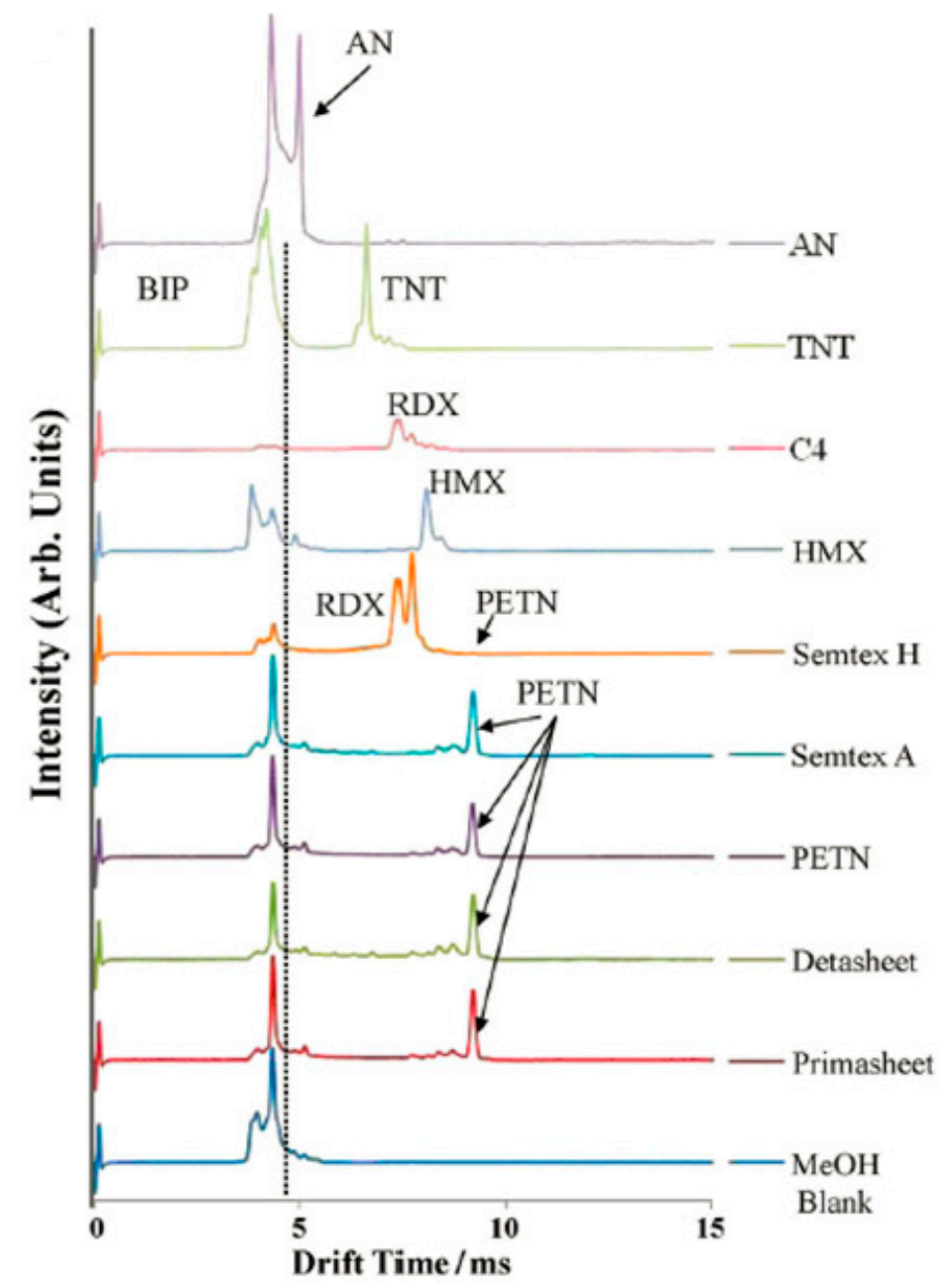

Figure 16. Ion mobility spectra of different explosives. Adapted from [132], with permission from $\odot$ 2010 Elsevier.

Solid phase micro-extraction (SPME) was coupled with IMS as a sample pre-concentration system to improve the detection of explosive residues in open areas [133]. The detection ability for DNT and TNT was obtained. Nitrocellulose (NC) spectra could also be measured by the SPME-IMS system on a reliable basis. The results indicated that this technique was useful as a potential screening tool for energetic compounds.

\section{Conclusions and Future Prospects}

The detection of explosives and related compounds has become a high priority issue in recent years for security reasons. From this review, it can be conducted that considerable progress has been achieved in different spectroscopic techniques (THz spectroscopy, LIBS, Raman spectroscopy, and IMS) for detecting various explosives. Comparisons of several properties are given in Table 4, based on referenced papers as well as subjective assessments. Additionally, there are thousands of explosive compounds and no single approach is capable of detecting every such compound. 
Table 4. Comparison of the four spectroscopic detection technologies.

\begin{tabular}{cccccc}
\hline Methods & Sample Type & Sensitivity & Molecular Selectivity & Acquisition Time & In Situ Monitoring \\
\hline THz spectroscopy & condensed & medium & good & fast & Yes \\
LIBS & condensed & low & medium & fast & Yes \\
Raman spectroscopy & condensed & medium & good & slow & Yes \\
IMS & gas & high & medium & medium & Yes \\
\hline
\end{tabular}

The use of terahertz technology to detect explosives from various sources has attracted much interest. However, so far these attempts have only been partially successful. One major reason is that current terahertz spectroscopy techniques allow the collection of spectra in a narrow terahertz window, only up to 3-6 THz. In this range, many compounds may appear similar; this window is not sufficient to distinguish the different explosives and their matrix separately. A wider terahertz bandwidth is expected to identify the salient features in the acquired spectrum unique to each molecule. Since the reflection of hazardous materials is weak and the dependence on the surface quality is strong, this measurement requires a more sensitive arrangement and careful signal processing to achieve reliable results. To avoid the problem of peak broadening, a waveguide-based TDS technique can be used in which the crystal plane is highly oriented to the emitted $\mathrm{THz}$ radiation.

In order to make explosive detection more reliable, LIBS still has some difficulties to overcome. As mentioned earlier, when an attempt is made to detect explosives, interference from atmospheric oxygen and nitrogen is a problem, and a system designed to prioritize remnants can help eliminate peripheral interference. Moreover, the dual pulse LIBS can reduce the contribution of the ambient atmosphere.

Further research through the use of portable Raman microscopes will also be useful so that testing whether the explosive particles can be carried out in the battlefield from the explosive mixture is a crucial aspect of the military actions. Actually, the current portable Raman spectrometer usually does not combine the microscope, so they are only applicable to the detection of massive unexploded explosives.

Ion mobility spectrometry is a widely used method for detecting explosives before detonation. It has the advantages of firmness, portability, and on-site use. Nevertheless, the research work carried out in the analytical laboratory has certain limits: low resolving power, limited selectivity, and chemical interference, so they are not always directly applicable to the comprehensive screening of various explosives. For the ion mobility spectrometry, future development directions are miniaturization, substitution of non-radioactive ionization sources, and improvement of instrument performance.

The combination of various methods is an effective way to ensure accurate detection. By sharing lasers, spectrometers, and optical paths, a combination of different spectral methods (such as Raman and LIBS) can be implemented in a single instrument, and various efforts are required to reduce the size and complexity of the instrument $[134,135]$. In addition, new analytical methods need to be developed to detect explosives faster and more sensitively. The technique of explosive detection is ideal for rapid real-time analysis of the minimum quantity of explosives with high precision and resolution without involving the preparation of complex samples. The continuous development of these testing technologies will result in new or even more precise applications, and the demand for the fast and reliable detection of energetic materials is increasing. At present, the Spectroscopy-based detection techniques are the most advanced in the field of explosion analysis. Therefore, it is foreseeable that they will also play a crucial role in the future. Improving the sensitivity and specificity of explosives detection technology are important principles.

Author Contributions: Y.T. and A.S. performed the bibliographic search, L.B and Y.S. prepared the tables and figures. W.Z. wrote the review, R.S. and Y.Y revised the manuscript. All authors read the draft, provided corrections, and approved the final version.

Funding: This research was funded by the National Natural Science Foundation of China (Grant No. 11604149) and the Fundamental Research Funds for the Central Universities (Grant No. 30918011315). 
Acknowledgments: We express our sincere gratitude to the authors of all references for their excellent work and we also are very grateful for the reviewers for their careful review.

Conflicts of Interest: The authors declare no conflict of interests.

\section{References}

1. Lefferts, M.J.; Castell, M.R. Vapour sensing of explosive materials. Anal. Methods 2015, 7, 9005-9017. [CrossRef]

2. Zandieh, O.; Kim, S. Sensitive and selective detection of adsorbed explosive molecules using opto-calorimetric infrared spectroscopy and micro-differential thermal analysis. Sens. Actuators B Chem. 2016, 231, 393-398. [CrossRef]

3. Gares, K.L.; Hufziger, K.T.; Bykov, S.V.; Asher, S.A. Review of explosive detection methodologies and the emergence of standoff deep UV resonance Raman. J. Raman Spectrosc. 2016, 47, 124-141. [CrossRef]

4. Lu, W.; Dong, X.; Qiu, L.; Yan, Z.; Meng, Z.; Xue, M.; He, X.; Liu, X. Colorimetric sensor arrays based on pattern recognition for the detection of nitroaromatic molecules. J. Hazard. Mater. 2017, 326, 130-137. [CrossRef] [PubMed]

5. López-López, M.; García-Ruiz, C. Infrared and Raman spectroscopy techniques applied to identification of explosives. Trends Anal. Chem. 2013, 54, 36-44.

6. Mäkinen, M.; Nousiainen, M.; Sillanpää, M. Ion spectrometric detection technologies for ultra-traces of explosives: A review. Mass Spectrom. Rev. 2011, 30, 940-973. [CrossRef] [PubMed]

7. Zarei, A.R.; Ghazanchayi, B. Design and fabrication of optical chemical sensor for detection of nitroaromatic explosives based on fluorescence quenching of phenol red immobilized poly(vinyl alcohol) membrane. Talanta 2016, 150, 162-168. [CrossRef] [PubMed]

8. Pramanik, S.; Zheng, C.; Zhang, X.; Emge, T.J.; Li, J. New microporous metal-organic framework demonstrating unique selectivity for detection of high explosives and aromatic compounds. J. Am. Chem. Soc. 2011, 133, 4153-4155. [CrossRef] [PubMed]

9. Demiră̆, Y.; Bütün, B.; Özbay, E. Plasmonic enhanced terahertz time-domain spectroscopy system for identification of common explosives. In Proceedings of the Next-Generation Spectroscopic Technologies X, Anaheim, CA, USA, 5 May 2017.

10. Greenall, N.; Valavanis, A.; Desai, H.; Acheampong, D.; Li, L.; Cunningham, J.; Davies, A.; Linfield, E.; Burnett, A. The Development of a Semtex-H Simulant for Terahertz Spectroscopy. J. Infrared Millim. Terahertz Waves 2017, 38, 325-338. [CrossRef]

11. Lucena, P.; Doña, A.; Tobaria, L.; Laserna, J. New challenges and insights in the detection and spectral identification of organic explosives by laser induced breakdown spectroscopy. Spectrochim. Acta Part B 2011, 66, 12-20. [CrossRef]

12. Gavenda, T.; Křesálek, V. Terahertz time-domain spectroscopy for distinguishing different kinds of gunpowder. In Proceedings of the Millimetre Wave and Terahertz Sensors and Technology VI, Dresden, Germany, 18 October 2013.

13. Wang, Z.; Yuan, T.-B.; Hou, Z.-Y.; Zhou, W.-D.; Lu, J.-D.; Ding, H.-B.; Zeng, X.-Y. Laser-induced breakdown spectroscopy in China. Front. Phys. 2014, 9, 419-438. [CrossRef]

14. Zhang, W.; Ma, X.; Shen, R.; Wu, L.; Ye, Y.; Hu, Y.; Zhu, P. Progress on laser-induced decomposition of explosives investigated by spectroscopic methods. Appl. Spectrosc. Rev. 2014, 49, 550-563. [CrossRef]

15. Zhang, W.; Shen, R.; Wu, L.; Ye, Y.; Hu, Y. Experimental studies on plasma emission spectroscopy of laser ablation of hexahydro-1, 3, 5-trinitro-1,3,5-triazine. In Proceedings of the 2nd International Symposium on Laser Interaction with Matter (LIMIS 2012), Xi'an, China, 16 May 2013.

16. Yang, C.S.-C.; Jin, F.; Trivedi, S.B.; Brown, E.E.; Hommerich, U.; Tripathi, A.; Samuels, A.C. Long-wave infrared (LWIR) molecular laser-induced breakdown spectroscopy (LIBS) emissions of thin solid explosive powder films deposited on aluminum substrates. Appl. Spectrosc. 2017, 71, 728-734. [CrossRef] [PubMed]

17. Botti, S.; Almaviva, S.; Cantarini, L.; Palucci, A.; Puiu, A.; Rufoloni, A. Trace level detection and identification of nitro-based explosives by surface-enhanced Raman spectroscopy. J. Raman Spectrosc. 2013, 44, 463-468. [CrossRef]

18. Malka, I.; Rosenwaks, S.; Bar, I. Photo-guided sampling for rapid detection and imaging of traces of explosives by a compact Raman spectrometer. Appl. Phys. Lett. 2014, 104, 221103. [CrossRef] 
19. Piorek, B.D.; Lee, S.J.; Moskovits, M.; Meinhart, C.D. Free-surface microfluidics/surface-enhanced Raman spectroscopy for real-time trace vapor detection of explosives. Anal. Chem. 2012, 84, 9700-9705. [CrossRef] [PubMed]

20. Butler, H.J.; Ashton, L.; Bird, B.; Cinque, G.; Curtis, K.; Dorney, J.; Esmonde-White, K.; Fullwood, N.J.; Gardner, B.; Martin-Hirsch, P.L.; et al. Using Raman spectroscopy to characterize biological materials. Nat. Protoc. 2016, 11, 664-687. [CrossRef] [PubMed]

21. Farhadian, A.; Tehrani, M.K.; Keshavarz, M.; Darbani, S. Raman spectroscopy combined with principle component analysis to investigate the aging of high energy materials. Laser Phys. 2017, 27, 075701. [CrossRef]

22. Guven, B.; Eryilmaz, M.; Üzer, A.; Boyaci, I.H.; Tamer, U.; Apak, R. Surface-enhanced Raman spectroscopy combined with gold nanorods for the simultaneous quantification of nitramine energetic materials. RSC Adv. 2017, 7, 37039-37047. [CrossRef]

23. Buryakov, I.A. Detection of explosives by ion mobility spectrometry. J. Anal. Chem. 2011, 66, 674. [CrossRef]

24. Filipenko, A.A.; Malkin, E.K. Study of the effect of ionization conditions on the mass selective distributions of the ion mobilities of trotyl and hexogen by ion mobility spectrometry-tandem mass spectrometry. J. Anal. Chem. 2011, 66, 1324-1332. [CrossRef]

25. Gaik, U.; Sillanpää, M.; Witkiewicz, Z.; Puton, J. Nitrogen oxides as dopants for the detection of aromatic compounds with ion mobility spectrometry. Anal. Bioanal. Chem. 2017, 409, 3223-3231. [CrossRef] [PubMed]

26. Hagan, N.; Goldberg, I.; Graichen, A.; Jean, A.S.; Wu, C.; Lawrence, D.; Demirev, P. Ion mobility spectrometry-high resolution LTQ-Orbitrap mass spectrometry for analysis of homemade explosives. J. Am. Soc. Mass Spectrom. 2017, 28, 1531-1539. [CrossRef] [PubMed]

27. Krylatykh, N.A.; Fattakhov, Y.V.; Fakhrutdinov, A.R.; Anashkin, V.N.; Shagalov, V.A.; Khabipov, R.S. Detection of explosive precursors using low-field magnetic resonance imaging. Appl. Magn. Reson. 2016, 47, 915-924. [CrossRef]

28. Balc1, E.; Rameev, B.; Acar, H.; Mozzhukhin, G.V.; Aktaş, B.; Çolak, B.; Kupriyanov, P.A.; Ievlev, A.V.; Chernyshev, Y.S.; Chizhik, V.I. Development of Earth's field nuclear magnetic resonance (EFNMR) technique for applications in security scanning devices. Appl. Magn. Reson. 2016, 47, 87-99. [CrossRef]

29. Rameev, B.Z.; Aktaş, B. NMR \& MW techniques for detection of explosive and illicit materials. In Proceedings of the 2016 9th International Kharkiv Symposium on Physics and Engineering of Microwaves, Millimeter and Submillimeter Waves (MSMW), Kharkiv, Ukraine, 20-24 June 2016; pp. 1-3.

30. Apih, T.; Rameev, B.; Mozzhukhin, G.; Barras, J. Magnetic Resonance Detection of Explosives and Illicit Materials; Springer: Berlin, Germany, 2013.

31. Hemnani, P.; Joshi, G.; Rajarajan, A.; Ravindranath, S. ${ }^{14} \mathrm{~N}$ NQR spectrometer for explosive detection: A review. In Proceedings of the 2016 International Conference on Automatic Control and Dynamic Optimization Techniques (ICACDOT), Pune, India, 9-10 September 2016; pp. 1120-1125.

32. Cardona, L.; Miyato, Y.; Itozaki, H.; Jiménez, J.; Vanegas, N.; Sato-Akaba, H. Remote detection of ammonium nitrate by nuclear quadrupole resonance using a portable system. Appl. Magn. Reson. 2015, 46, 95-307. [CrossRef]

33. Cooper, R.J.; Mark, B.L.; Prescott, D.W.; Sauer, K.L. Improving the design of atomic magnetometer arrays for RF interference mitigation in NQR detection of explosives. In Proceedings of the Detection and Sensing of Mines, Explosive Objects, and Obscured Targets XXII, Anaheim, CA, USA, 4 May 2017.

34. Galan-Freyle, N.J.; Pacheco-Londono, L.C.; Figueroa-Navedo, A.M.; Hernandez-Rivera, S.P. Standoff detection of highly energetic materials using laser-induced thermal excitation of infrared emission. Appl. Spectrosc. 2015, 69, 535-544. [CrossRef] [PubMed]

35. Figueroanavedo, A.; Pachecolondoño, L.C.; Hernándezrivera, S.P. Improved detection of highly energetic materials traces on surfaces by standoff laser-induced thermal emission incorporating neural networks. In Proceedings of the Thermosense: Thermal Infrared Applications XXXV, Baltimore, MD, USA, 3 June 2013.

36. Castro-Suarez, J.R.; Pacheco-Londoño, L.C.; Aparicio-Bolaño, J.; Hernández-Rivera, S.P. Active mode remote infrared spectroscopy detection of TNT and PETN on aluminum substrates. J. Spectrosc. 2017, 2017, 2730371. [CrossRef]

37. Breshike, C.J.; Kendziora, C.A.; Furstenberg, R.; Nguyen, V.; McGill, R.A. Methodology for using active infrared spectroscopy in standoff detection of trace explosives. In Proceedings of the Chemical, Biological, Radiological, Nuclear, and Explosives (CBRNE) Sensing XVIII, Anaheim, CA, USA, 3 May 2017. 
38. Ewing, A.V.; Kazarian, S.G. Infrared spectroscopy and spectroscopic imaging in forensic science. Analyst 2017, 142, 257-272. [CrossRef] [PubMed]

39. Ong, T.-H.; Mendum, T.; Geurtsen, G.; Kelley, J.; Ostrinskaya, A.; Kunz, R. Use of mass spectrometric vapor analysis to improve canine explosive detection efficiency. Anal. Chem. 2017, 89, 6482-6490. [CrossRef] [PubMed]

40. Civiš, S.; Civiš, M.; Sovová, K.; Dryahina, K.; Kubišta, J.; Skřehot, P.; Španěl, P.; Kyncl, M. Selected ion flow tube mass spectrometry analyses of laser decomposition products of a range of explosives and ballistic propellants. Anal. Methods 2016, 8, 1145-1150. [CrossRef]

41. Sisco, E.; Najarro, M.; Samarov, D.; Lawrence, J. Quantifying the stability of trace explosives under different environmental conditions using electrospray ionization mass spectrometry. Talanta 2017, 165, 10-17. [CrossRef] [PubMed]

42. Gamble, S.C.; Campos, L.C.; Morgan, R.M. Detection of trace peroxide explosives in environmental samples using solid phase extraction and liquid chromatography mass spectrometry. Environ. Forensics 2017, 18, 50-61. [CrossRef]

43. Sun, W.; Liang, M.; Li, Z.; Shu, J.; Yang, B.; Xu, C.; Zou, Y. Ultrasensitive detection of explosives and chemical warfare agents by low-pressure photoionization mass spectrometry. Talanta 2016, 156, 191-195. [CrossRef] [PubMed]

44. Zhang, W.; Shen, R.; Ye, Y.; Wu, L.; Zhu, P.; Hu, Y. Distribution and formation of particles produced by laser ablation of cyclotetramethylene tetranitramine. Laser Part. Beams 2017, 35, 391-396. [CrossRef]

45. Zhang, W.; Shen, R.; Ye, Y.; Wu, L.; Hu, Y.; Zhu, P. Dissociation of Cyclotrimethylenetrinitramine Under 1064-nm Laser Irradiation Investigated by Time-of-Flight Mass Spectrometer. Spectrosc. Lett. 2014, 47, 611-615. [CrossRef]

46. Zhang, W.; Wang, F.; Shen, R.; Ye, Y. Time of flight mass spectroscopy of 2,2' 4 4, $4^{\prime}, 6,6^{\prime}$-hexanitrostilbene under $1064 \mathrm{~nm}$ excitation. In Proceedings of the Fourth International Symposium on Laser Interaction with Matter, Chengdu, China, 12 May 2017.

47. Fujiyama-Novak, J.H.; Gaddam, C.K.; Das, D.; Vander Wal, R.L.; Ward, B. Detection of explosives by plasma optical emission spectroscopy. Sensor Actuators B-Chem. 2013, 176, 985-993. [CrossRef]

48. Vander Wal, R.L.; Gaddam, C.K.; Kulis, M.J. An investigation of micro-hollow cathode glow discharge generated optical emission spectroscopy for hydrocarbon detection and differentiation. Appl. Spectrosc. 2014, 68, 649-656. [CrossRef] [PubMed]

49. Furstenberg, R.; Kendziora, C.A.; Papantonakis, M.R.; Mcgill, R.A. Trace explosives detection using photo-thermal infrared imaging spectroscopy (PT-IRIS): theory, modeling, and detection algorithms. In Proceedings of the Chemical, Biological, Radiological, Nuclear, and Explosives (CBRNE) Sensing XVI, Baltimore, MD, USA, 19 May 2015.

50. Kendziora, C.A.; Furstenberg, R.; Papantonakis, M.; Nguyen, V.; McGill, R.A. Broadband infrared imaging spectroscopy for standoff detection of trace explosives. In Proceedings of the Micro- and Nanotechnology Sensors, Systems, and Applications VIII, Baltimore, MD, USA, 25 May 2016.

51. Kendziora, C.A.; Furstenberg, R.; Papantonakis, M.; Nguyen, V.; Byers, J.; McGill, R.A. Infrared photothermal imaging spectroscopy for detection of trace explosives on surfaces. Appl. Opt. 2015, 54, 129-138. [CrossRef] [PubMed]

52. Marcus, L.S.; Holthoff, E.L.; Pellegrino, P.M. Standoff photoacoustic spectroscopy of explosives. Appl. Spectrosc. 2017, 71, 833-838. [CrossRef] [PubMed]

53. Holthoff, E.L.; Marcus, L.S.; Pellegrino, P.M. Photoacoustic spectroscopy for trace vapor detection and standoff detection of explosives. In Proceedings of the Chemical, Biological, Radiological, Nuclear, and Explosives (CBRNE) Sensing XVII, Baltimore, MD, USA, 12 May 2016.

54. Puiu, A.; Giubileo, G.; Cesaro, S.N.; Palucci, A. Application of Laser photoacoustic spectroscopy and chemometrics in homeland security. In Photoptics 2015; Springer: Berlin, Germany, 2016; pp. 53-62.

55. Cuisset, A.; Gruet, S.; Pirali, O.; Chamaille, T.; Mouret, G. Synchrotron FT-FIR spectroscopy of nitro-derivatives vapors: New spectroscopic signatures of explosive taggants and degradation products. Spectroc. Acta Part A Mol. Biomol. Spectrosc. 2014, 132, 838-845. [CrossRef] [PubMed]

56. Qin, T.; Wang, X.; Meng, H.; Qin, Y.X.; Webb, B.; Wan, G.B.; Witte, R.S.; Xin, H. Microwave-induced thermoacoustic imaging for embedded explosives detection. In Proceedings of the IEEE Antennas and Propagation Society International Symposium, Memphis, TN, USA, 6-11 July 2014; pp. 1917-1918. 
57. Roucou, A.; Kleiner, I.; Goubet, M.; Bteich, S.; Mouret, G.; Bocquet, R.; Hindle, F.; Meerts, W.L.; Cuisset, A. Towards the detection of explosive taggants: Microwave and millimetre-wave gas-phase spectroscopies of 3-Nitrotoluene. Chemphyschem 2018, 19, 1056-1067. [CrossRef] [PubMed]

58. Wells, K.; Bradley, D. A review of X-ray explosives detection techniques for checked baggage. Appl. Radiat. Isot. 2012, 70, 1729-1746. [CrossRef] [PubMed]

59. Gierlik, M.; Borsuk, S.; Guzik, Z.; Iwanowska, J.; Korolczuk, S.; Kozłowski, T.; Krakowski, T.; Marcinkowski, R.; Swiderski, L.; Szeptycka, M. SWAN-Detection of explosives by means of fast neutron activation analysis. Methods Phys. Res. Sect. A 2016, 834, 16-23. [CrossRef]

60. Yin, M.; Tang, S.; Tong, M. The application of Terahertz spectroscopy to liquid petrochemicals detection: A review. Appl. Spectrosc. Rev. 2016, 51, 379-396. [CrossRef]

61. Baxter, J.B.; Guglietta, G.W. Terahertz spectroscopy. Anal. Chem. 2011, 83, 4342-4368. [CrossRef] [PubMed]

62. Han, S.; Bertling, K.; Dean, P.; Keeley, J.; Burnett, A.D.; Lim, Y.L.; Khanna, S.P.; Valavanis, A.; Linfield, E.H.; Davies, A.G. Laser feedback interferometry as a tool for analysis of granular materials at terahertz frequencies: towards imaging and identification of plastic explosives. Sensors 2016, 16, 352. [CrossRef] [PubMed]

63. Skvortsov, L.A. Standoff Detection of Hidden Explosives and Cold and Fire Arms by Terahertz Time-Domain Spectroscopy and Active Spectral Imaging (Review). J. Appl. Spectrosc. 2014, 81, 725-749. [CrossRef]

64. Palka, N.; Szala, M.; Czerwinska, E. Characterization of prospective explosive materials using terahertz time-domain spectroscopy. Appl. Opt. 2016, 55, 4575-4583. [CrossRef] [PubMed]

65. Lepodise, L.M.; Horvat, J.; Lewis, R.A. Terahertz Spectroscopy of 2,4-Dinitrotoluene over a Wide Temperature Range (7-245 K). J. Phys. Chem. A 2015, 119, 263-270. [CrossRef] [PubMed]

66. Pierno, L.; Fiorello, A.M.; Scafè, S.; Cunningham, J.; Burnett, A.D.; Linfield, E.H.; Davies, A.G. THz-TDS analysis of hidden explosives for homeland security scenarios. In Proceedings of the 2013 6th UK, European, China Millimeter Waves and THz Technology Workshop, Rome, Italy, 9-11 September 2013; pp. 1-2.

67. Trofimov, V.A.; Varentsova, S.A.; Zakharova, I.G.; Zagursky, D.Y. Principal limitation of standard THz time-domain spectroscopy method of the detection and identification of substance and way of its overcoming. In Proceedings of the Optics and Photonics for Counterterrorism, Crime Fighting, and Defence XI; and Optical Materials and Biomaterials in Security and Defence Systems Technology XII, Toulouse, France, 21 October 2015.

68. Smith, R.M.; Arnold, M.A. Terahertz time-domain spectroscopy of solid samples: principles, applications, and challenges. Appl.Spectrosc. Rev. 2011, 46, 636-679. [CrossRef]

69. Sleiman, J.B.; Bousquet, B.; Palka, N.; Mounaix, P. Quantitative analysis of hexahydro-1,3,5-trinitro-1,3,5, triazine/pentaerythritol tetranitrate (RDX -PETN) mixtures by terahertz time domain spectroscopy. Appl. Spectrosc. 2015, 69, 1464-1471. [CrossRef] [PubMed]

70. Sleiman, J.B.; Perraud, J.-B.; Bousquet, B.; Guillet, J.-P.; Palka, N.; Mounaix, P. Identifying explosives by chemometrics with terahertz spectral imaging. SPIE Newsroom 2015. [CrossRef]

71. Bousleiman, J.; Perraud, J.B.; Palka, N.; Mounaix, P. Discrimination and identification of RDX/PETN explosives by chemometrics applied to terahertz time-domain spectral imaging. In Proceedings of the Millimetre Wave and Terahertz Sensors and Technology VIII, Toulouse, France, 21 October 2015.

72. Trzcinski, T.; Palka, N.; Szustakowski, M. THz spectroscopy of explosive-related simulants and oxidizers. Polska Akad. Nauk. Bull. Pol. Acad. Sci. 2011, 59, 445. [CrossRef]

73. Rahman, A. Dendrimer based terahertz time-domain spectroscopy and applications in molecular characterization. J. Mol. Struct. 2011, 1006, 59-65. [CrossRef]

74. Palka, N. THz reflection spectroscopy of explosives measured by time domain spectroscopy. Acta Phys. Pol. A 2011, 120, 713-715. [CrossRef]

75. Choi, K.; Hong, T.; Ik Sim, K.; Ha, T.; Cheol Park, B.; Hyuk Chung, J.; Gyeong Cho, S.; Hoon Kim, J. Reflection terahertz time-domain spectroscopy of RDX and HMX explosives. J. Appl. Phys. 2014, 115, 023105. [CrossRef]

76. Huang, P.; Qiu, R.; Tang, Y.X. Study on terahertz spectroscopic of energetic ion salt and oxidizer. J. Microw. Power Electromagn. Energy 2015, 49, 21-28.

77. Huang, P.; Shi, W. Study on Terahertz time-domain spectroscopy of HNS by sample measure and quantum chemistry calculation. Propellants Explos. Pyrotech. 2011, 36, 513-518. [CrossRef]

78. Meng, Z.-R.; Shang, L.-P.; Du, Y.; Deng, H. Absorption characteristics and simulation of LLM-105 in the Terahertz range. Guangpuxue Yu Guangpu Fenxi 2015, 35, 1779-1782. 
79. Meng, Z.R.; Shang, L.P.; Du, Y.; Deng, H. Absorption characteristics and simulation of FOX-7 in the terahertz range. Guangpuxue Yu Guangpu Fenxi 2015, 44, 1121-1125.

80. Du, Y.; Li, J.-M.; Zong, H.-H.; Yang, Z.-F.; Zhang, W.-B. Absorption spectrum studies on the RDX crystals with different granularity in terahertz frequency range. J. Electron. Sci. Technol. 2014, 12, 150-155.

81. Guo, L.; Zhang, L.; Wang, X.; Hu, Y.; Zhang, C. Time-resolved terahertz spectroscopy of explosive materials. Chin. Opt. Lett. 2005, 3, 117-119.

82. Choi, J.; Ryu, S.Y.; Kwon, W.S.; Kim, K.-S.; Kim, S. Compound explosives detection and component analysis via terahertz time-domain spectroscopy. J. Opt. Soc. Korea 2013, 17, 454-460. [CrossRef]

83. Chrzanowski, L.S.V.; Beckmann, J.; Marchetti, B.; Ewert, U.; Schade, U. Terahertz time domain spectroscopy for non-destructive testing of hazardous liquids. Mater. Test. 2012, 54, 444-450. [CrossRef]

84. Puc, U.; Abina, A.; Rutar, M.; Zidansek, A.; Jeglic, A.; Valusis, G. Terahertz spectroscopic identification of explosive and drug simulants concealed by various hiding techniques. Appl. Opt. 2015, 54, 4495-4502. [CrossRef] [PubMed]

85. Wang, Z.-Z.; Deguchi, Y.; Zhang, Z.-Z.; Wang, Z.; Zeng, X.-Y.; Yan, J.-J. Laser-induced breakdown spectroscopy in Asia. Front. Phys. 2016, 11, 114213. [CrossRef]

86. Fountain, A.W.; Christesen, S.D.; Moon, R.P.; Guicheteau, J.A.; Emmons, E.D. Recent advances and remaining challenges for the spectroscopic detection of explosive threats. Appl. Spectrosc. 2014, 68, 795-811. [CrossRef] [PubMed]

87. Pellegrino, P.M.; Holthoff, E.L.; Farrell, M.E. Laser-based optical detection of explosives; CRC Press: Boca Raton, FL, USA, 2015; Volume 40.

88. Johnson, J.B.; Allen, S.D.; Merten, J.; Johnson, L.; Pinkham, D.; Reeve, S.W. Standoff methods for the detection of threat agents: A review of several promising laser-based techniques. J. Spectrosc. 2014, 2014, 613435. [CrossRef]

89. Leahy-Hoppa, M.R.; Miragliotta, J.; Osiander, R.; Burnett, J.; Dikmelik, Y.; McEnnis, C.; Spicer, J.B. Ultrafast laser-based spectroscopy and sensing: applications in LIBS, CARS, and THz spectroscopy. Sensors 2010, 10, 4342-4372. [CrossRef] [PubMed]

90. Rao, E.N.; Mathi, P.; Kalam, S.A.; Sreedhar, S.; Singh, A.K.; Jagatap, B.; Rao, S.V. Femtosecond and nanosecond LIBS studies of nitroimidazoles: Correlation between molecular structure and LIBS data. J. Anal. At. Spectrom. 2016, 31, 737-750. [CrossRef]

91. Ahmido, T.; Ting, A.; Misra, P. Femtosecond laser-induced breakdown spectroscopy of surface nitrate chemicals. Appl. Opt. 2013, 52, 3048-3057. [CrossRef] [PubMed]

92. Markiewicz-Keszycka, M.; Cama-Moncunill, X.; Casado-Gavalda, M.P.; Dixit, Y.; Cama-Moncunill, R.; Cullen, P.J.; Sullivan, C. Laser-induced breakdown spectroscopy (LIBS) for food analysis: a review. Trends Food Sci. Technol. 2017, 65, 80-93. [CrossRef]

93. Serrano, J.; Moros, J.; Javier Laserna, J. Molecular signatures in femtosecond laser-induced organic plasmas: Comparison with nanosecond laser ablation. Phys. Chem. Chem. Phys. 2016, 18, 2398-2408. [CrossRef] [PubMed]

94. Moros, J.; Laserna, J.J. A spectral sieve-based strategy for sensing inorganic and organic traces on solid surfaces using laser-induced breakdown spectroscopy. Anal. Methods 2015, 7, 7280-7289. [CrossRef]

95. Moros, J.; Serrano, J.; Gallego, F.J.; Macias, J.; Laserna, J.J. Recognition of explosives fingerprints on objects for courier services using machine learning methods and laser-induced breakdown spectroscopy. Talanta 2013, 110, 108-117. [CrossRef] [PubMed]

96. Yang, C.S.C.; Brown, E.E.; Hommerich, U.; Jin, F.; Trivedi, S.B.; Samuels, A.C.; Snyder, A.P. Long-wave, infrared laser-induced breakdown (LIBS) spectroscopy emissions from energetic materials. Appl. Spectrosc. 2012, 66, 1397-1402. [CrossRef] [PubMed]

97. Li, W.; Lu, J.; Dong, M.; Lu, S.; Yu, J.; Li, S.; Huang, J.; Liu, J. Quantitative analysis of calorific value of coal based on spectral preprocessing by laser-induced breakdown spectroscopy (LIBS). Energy Fuels 2017, 32, 24-32. [CrossRef]

98. Myakalwar, A.K.; Spegazzini, N.; Zhang, C.; Anubham, S.K.; Dasari, R.R.; Barman, I.; Gundawar, M.K. Less is more: Avoiding the LIBS dimensionality curse through judicious feature selection for explosive detection. Sci. Rep. 2015, 5, 10. [CrossRef] [PubMed] 
99. Yang, C.S.; Brown, E.; Hommerich, U.; Trivedi, S.B.; Samuels, A.C.; Snyder, A.P. Infrared laser-induced breakdown spectroscopy emissions from energetic materials. In Proceedings of the Chemical, Biological, Radiological, Nuclear, and Explosives (CBRNE) Sensing XII, Orlando, FL, USA, May 2011.

100. Sunku, S.; Gundawar, M.K.; Myakalwar, A.K.; Kiran, P.P.; Tewari, S.P.; Rao, S.V. Femtosecond and nanosecond laser induced breakdown spectroscopic studies of NTO, HMX, and RDX. Spectrochim. Acta 2013, 79-80, 31-38. [CrossRef]

101. Sreedhar, S.; Nageswara Rao, E.; Manoj Kumar, G.; Tewari, S.P.; Venugopal Rao, S. Molecular formation dynamics of 5-nitro-2,4-dihydro-3H-1,2,4-triazol-3-one, 1,3,5-trinitroperhydro-1,3,5-triazine, and 2,4,6-trinitrotoluene in air, nitrogen, and argon atmospheres studied using femtosecond laser induced breakdown spectroscopy. Spectrochim. Acta 2013, 87, 121-129. [CrossRef]

102. Rao, E.N.; Sunku, S.; Rao, S.V. Femtosecond laser-induced breakdown spectroscopy studies of nitropyrazoles: the effect of varying nitro groups. Appl. Spectrosc. 2015, 69, 1342-1354. [CrossRef] [PubMed]

103. Nageswara Rao, E.; Sunku, S.; Tewari, S.P.; Manoj Kumar, G.; Venugopal Rao, S. Femtosecond LIBS studies of nitropyrazoles. In Proceedings of the Chemical, Biological, Radiological, Nuclear, and Explosives (CBRNE) Sensing XIV, Baltimore, MD, USA, 29 May 2013.

104. Delgado, T.; Vadillo, J.M.; Laserna, J.J. Primary and recombined emitting species in laser-induced plasmas of organic explosives in controlled atmospheres. J. Anal. At. Spectrom. 2014, 29, 1675-1685. [CrossRef]

105. De Lucia, F.C.; Gottfried, J.L. Influence of molecular structure on the laser-induced plasma emission of the explosive RDX and organic polymers. J. Phys. Chem. A 2013, 117, 9555-9563. [CrossRef] [PubMed]

106. Rezaei, A.H.; Keshavarz, M.H.; Tehrani, M.K.; Darbani, S.M.R.; Farhadian, A.H.; Jabbarmousavi, S.; Mousaviazar, A. Approach for determination of detonation performance and aluminum percentage of aluminized-based explosives by laser-induced breakdown spectroscopy. Appl. Opt. 2016, 55, 3233-3240. [CrossRef] [PubMed]

107. De Lucia, F.C.; Gottfried, J.L. Characterization of a series of nitrogen-rich molecules using laser induced breakdown spectroscopy. Propellants Explos. Pyrotech. 2010, 35, 268-277. [CrossRef]

108. Shaik, A.K.; Epuru, N.R.; Syed, H.; Byram, C.; Soma, V.R. Femtosecond laser induced breakdown spectroscopy based standoff detection of explosives and discrimination using principal component analysis. Opt. Express 2018, 26, 8069-8083. [CrossRef] [PubMed]

109. Khandasammy, S.R.; Fikiet, M.A.; Mistek, E.; Ahmed, Y.; Halámková, L.; Bueno, J.; Lednev, I.K. Bloodstains, paintings, and drugs: Raman spectroscopy applications in forensic science. Forensic Chem. 2018, 8, 111-133. [CrossRef]

110. Tuschel, D.D.; Mikhonin, A.V. Deep ultraviolet resonance Raman excitation enables explosives detection. Appl. Spectrosc. 2010, 64, 425-432. [CrossRef] [PubMed]

111. John, N.; George, S. Raman Spectroscopy. In Spectroscopic Methods for Nanomaterials Characterization; Elsevier: New York, NY, USA, 2017; pp. 95-127.

112. Almaviva, S.; Botti, S.; Cantarini, L.; Palucci, A.; Puiu, A.; Rufoloni, A.; Landstrom, L.; Romolo, F.S. Trace detection of explosives and their precursors by surface enhanced Raman spectroscopy. In Proceedings of the Optics and Photonics for Counterterrorism, Crime Fighting, and Defence VIII, Edinburgh, UK, 30 October 2012.

113. Jin, H.C.; Cho, S.G. Nanosecond Gated Raman Spectroscopy for Standoff Detection of Hazardous Materials. Bull. Korean Chem. Soc. 2014, 35, 3547-3552.

114. Ghosh, M.; Wang, L.; Asher, S.A. Deep-ultraviolet resonance raman excitation profiles of $\mathrm{NH}_{4} \mathrm{NO}_{3}, \mathrm{PETN}_{\text {, }}$ TNT, HMX, and RDX. Appl. Spectrosc. 2012, 66, 1013-1021. [CrossRef]

115. Hwang, J.; Choi, N.; Park, A.; Park, J.-Q.; Chung, J.H.; Baek, S.; Cho, S.G.; Baek, S.-J.; Choo, J. Fast and sensitive recognition of various explosive compounds using Raman spectroscopy and principal component analysis. J. Mol. Struct. 2013, 1039, 130-136. [CrossRef]

116. Nuntawong, N.; Eiamchai, P.; Limwichean, S.; Wong-Ek, B.; Horprathum, M.; Patthanasettakul, V.; Leelapojanaporn, A.; Nakngoenthong, S.; Chindaudom, P. Trace detection of perchlorate in industrial-grade emulsion explosive with portable surface-enhanced Raman spectroscopy. Forensic Sci. Int. 2013, 233, 174-178. [CrossRef] [PubMed]

117. Zapata, F.; Garcia-Ruiz, C. Determination of nanogram microparticles from explosives after real open-air explosions by confocal Raman microscopy. Anal. Chem. 2016, 88, 6726-6733. [CrossRef] [PubMed] 
118. Zhang, L.; Zheng, H.Y.; Wang, Y.P.; Ding, L.; Fang, L. Characteristics of Raman spectrum from stand-off detection. Acta Phys. Sin. 2016, 65, 054206.

119. Hufziger, K.T.; Bykov, S.V.; Asher, S.A. Ultraviolet Raman wide-field hyperspectral imaging spectrometer for standoff trace explosive detection. Appl. Spectrosc. 2016, 71, 173-185. [CrossRef] [PubMed]

120. Chen, N.; Ding, P.; Shi, Y.; Jin, T.; Su, Y.; Wang, H.; He, Y. Portable and reliable surface-enhanced Raman scattering silicon chip for signal-on detection of trace trinitrotoluene explosive in real systems. Anal. Chem. 2017, 89, 5072-5078. [CrossRef] [PubMed]

121. Zapata, F.; Lopez-Lopez, M.; Garcia-Ruiz, C. Detection and identification of explosives by surface enhanced Raman scattering. Appl. Spectrosc. Rev. 2016, 51, 207-242. [CrossRef]

122. Hakonen, A.; Andersson, P.O.; Schmidt, M.S.; Rindzevicius, T.; Kall, M. Explosive and chemical threat detection by surface-enhanced Raman scattering: A review. Anal. Chim. Acta 2015, 893, 1-13. [CrossRef] [PubMed]

123. Jamil, A.K.M.; Izake, E.L.; Sivanesan, A.; Fredericks, P.M. Rapid detection of TNT in aqueous media by selective label free surface enhanced Raman spectroscopy. Talanta 2015, 134, 732-738. [CrossRef] [PubMed]

124. Gillibert, R.; Huang, J.Q.; Zhang, Y.; Fu, W.L.; de la Chapelle, M.L. Explosive detection by surface enhanced raman scattering. TrAC Trends Anal. Chem. 2018, 105, 166-172. [CrossRef]

125. Emmons, E.D.; Guicheteau, J.A.; Christesen, S.D.; Fountain, A.W., III. Ultraviolet resonance Raman spectroscopy of nitroaromatic compounds for standoff detection applications. In Proceedings of the Chemical, Biological, Radiological, Nuclear, and Explosives (CBRNE) Sensing XII, Orlando, FL, USA, 6 June 2011.

126. Yellampelle, B.; Sluch, M.; Asher, S.; Lemoff, B. Multiple-excitation-wavelength resonance-Raman explosives detection. In Proceedings of the Chemical, Biological, Radiological, Nuclear, and Explosives (CBRNE) Sensing XII, Orlando, FL, USA, 3 June 2011.

127. Johnson, P.V.; Beegle, L.W.; Kim, H.I.; Eiceman, G.A.; Kanik, I. Ion mobility spectrometry in space exploration. Int. J. Mass Spectrom. 2007, 262, 1-15. [CrossRef]

128. Sivakumar, N.; Joseph, M.; Manoravi, P.; Vasudeva Rao, P.R.; Raj, B. Development of an ion mobility spectrometer for detection of explosives. Instrum. Sci. Technol. 2013, 41, 96-108. [CrossRef]

129. Lee, J.; Park, S.; Cho, S.G.; Goh, E.M.; Lee, S.; Koh, S.-S.; Kim, J. Analysis of explosives using corona discharge ionization combined with ion mobility spectrometry-mass spectrometry. Talanta 2014, 120, 64-70. [CrossRef] [PubMed]

130. Langmeier, A.; Heep, W.; Oberhuettinger, C.; Oberpriller, H.; Kessler, M.; Goebel, J.; Mueller, G. Detection and classification of explosive compounds utilizing laser ion mobility spectrometry. In Proceedings of the Chemical, Biological, Radiological, Nuclear, and Explosives (CBRNE) Sensing X, Orlando, FL, USA, 8 May 2009.

131. Tabrizchi, M.; Ilbeigi, V. Detection of explosives by positive corona discharge ion mobility spectrometry. J. Hazard. Mater. 2010, 176, 692-696. [CrossRef] [PubMed]

132. Hilton, C.K.; Krueger, C.A.; Midey, A.J.; Osgood, M.; Wu, J.; Wu, C. Improved analysis of explosives samples with electrospray ionization-high resolution ion mobility spectrometry (ESI-HRIMS). Int. J. Mass. Spectrom. 2010, 298, 64-71. [CrossRef]

133. Perr, J.M.; Furton, K.G.; Almirall, J.R. Application of a SPME-IMS detection system for explosives detection. In Proceedings of the SPIE-The International Society for Optical Engineering, Miami, FL, USA, May 2005.

134. Waterbury, R.; Blank, T.; Ford, A.; Dottery, E. Fabrication and testing of a standoff trace explosives detection system. In Proceedings of the Chemical, Biological, Radiological, Nuclear, and Explosives (CBRNE) Sensing XII, Orlando, FL, USA, 3 June 2011.

135. Moros, J.; Lorenzo, J.A.; Lucena, P.; Tobaria, L.M.; Laserna, J.J. Simultaneous Raman spectroscopy-laser-induced breakdown spectroscopy for instant standoff analysis of explosives using a mobile integrated sensor platform. Anal. Chem. 2010, 82, 1389. [CrossRef] [PubMed]

(C) 2018 by the authors. Licensee MDPI, Basel, Switzerland. This article is an open access article distributed under the terms and conditions of the Creative Commons Attribution (CC BY) license (http:/ / creativecommons.org/licenses/by/4.0/). 